\title{
The Close-Up Imager Onboard the ESA ExoMars Rover: Objectives, Description, Operations, and Science Validation Activities
}

\author{
Jean-Luc Josset,, Frances Westall, Beda A. Hofmann,3,4 John Spray, Charles Cockell, Stephan Kempe, \\ Andrew D. Griffiths, ${ }^{8}$ Maria Cristina De Sanctis, Luigi Colangeli, ${ }^{10}$ Detlef Koschny, ${ }^{10}$ Karl Föllmi, ${ }^{11}$ \\ Eric Verrecchia, ${ }^{12}$ Larryn Diamond, ${ }^{4}$ Marie Josset, ${ }^{1}$ Emmanuelle J. Javaux, ${ }^{13}$ Francesca Esposito, ${ }^{14}$ \\ Matthew Gunn, ${ }^{15}$ Audrey L. Souchon-Leitner, ${ }^{1}$ Tomaso R.R. Bontognali, ${ }^{16}$ Oleg Korablev, ${ }^{17}$ \\ Suren Erkman, ${ }^{18}$ Gerhard Paar, ${ }^{19}$ Stephan Ulamec, ${ }^{20}$ Frédéric Foucher, ${ }^{2}$ Philippe Martin, ${ }^{21}$ \\ Antoine Verhaeghe, Mitko Tanevski, and Jorge L. Vago ${ }^{10}$
}

\begin{abstract}
The Close-Up Imager (CLUPI) onboard the ESA ExoMars Rover is a powerful high-resolution color camera specifically designed for close-up observations. Its accommodation on the movable drill allows multiple positioning. The science objectives of the instrument are geological characterization of rocks in terms of texture, structure, and color and the search for potential morphological biosignatures. We present the CLUPI science objectives, performance, and technical description, followed by a description of the instrument's planned operations strategy during the mission on Mars. CLUPI will contribute to the rover mission by surveying the geological environment, acquiring close-up images of outcrops, observing the drilling area, inspecting the top portion of the drill borehole (and deposited fines), monitoring drilling operations, and imaging samples collected by the drill. A status of the current development and planned science validation activities is also given. Key Words: Mars-Biosignatures-Planetary Instrumentation. Astrobiology 17, 595-611.
\end{abstract}

\section{Introduction}

$\mathbf{F}$ OLLOWING ON THE recent exploration successes of NASA's 2003 Mars Exploration Rovers (Spirit and Opportunity) and 2011 Mars Science Laboratory (Curiosity), ESA will contribute to further our understanding of Mars with the launch of the 2020 ExoMars Rover.
ExoMars (e.g., Vago et al., 2013; Vago et al., 2017) is a collaboration program between ESA and Roscosmos consisting of two missions, ExoMars 2016 and ExoMars 2020. ExoMars 2016 was launched on March 14th, 2016 (e.g., Witasse et al., 2014), and consists of a Trace Gas Orbiter (TGO) plus an entry, descent, and landing demonstrator module (EDM, or Schiaparelli lander) that will land in

\footnotetext{
${ }^{1}$ Space Exploration Institute, Neuchâtel, Switzerland.

${ }^{2}$ Centre de Biophysique Moléculaire, CNRS, Orléans, France.

${ }^{3}$ Natural History Museum Bern, Bern, Switzerland.

${ }^{4}$ Institute of Geological Sciences, University of Bern, Bern, Switzerland.

${ }^{5}$ Planetary and Space Science, University of New Brunswick, New Brunswick, Canada.

${ }^{6}$ UK Center for Astrobiology, University of Edinburgh, Edinburgh, United Kingdom.

${ }^{7}$ Institute of Applied Geosciences, Technische Universität Darmstadt, Darmstadt, Germany.

${ }^{8}$ University College London, London, United Kingdom.

${ }^{9}$ Istituto di Astrofisica e Planetologia Spaziali, Roma, Italy.

${ }^{10}$ ESA, ESTEC, Noordwijk, The Netherlands.

${ }^{11}$ Faculty of Geosciences and Environment, Institut des sciences de la Terre, University of Lausanne, Lausanne, Switzerland.

${ }^{12}$ Faculty of Geosciences and Environment, Institute of Earth Surface Dynamics, University of Lausanne, Lausanne, Switzerland.

${ }^{13}$ Département de Géologie, UR GEOLOGY, University of Liège, Liège, Belgium.

${ }^{14}$ Osservatorio Astronomico di Capodimonte, Napoli, Italy.

${ }_{16}^{15}$ Department of Physics, Aberystwyth University, Wales, United Kingdom.

${ }^{16}$ Department of Earth Sciences, ETH Zurich, Zurich, Switzerland.

${ }^{17}$ Space Research Institute, IKI, Moscow, Russia.

${ }^{18}$ Faculty of Geosciences and Environment, University of Lausanne, Lausanne, Switzerland.

${ }^{19}$ Joanneum Research, Graz, Austria.

${ }^{20}$ DLR, Space Operations, MUSC, Cologne, Germany.

${ }^{21}$ LPC2E, Orléans, France.
} 


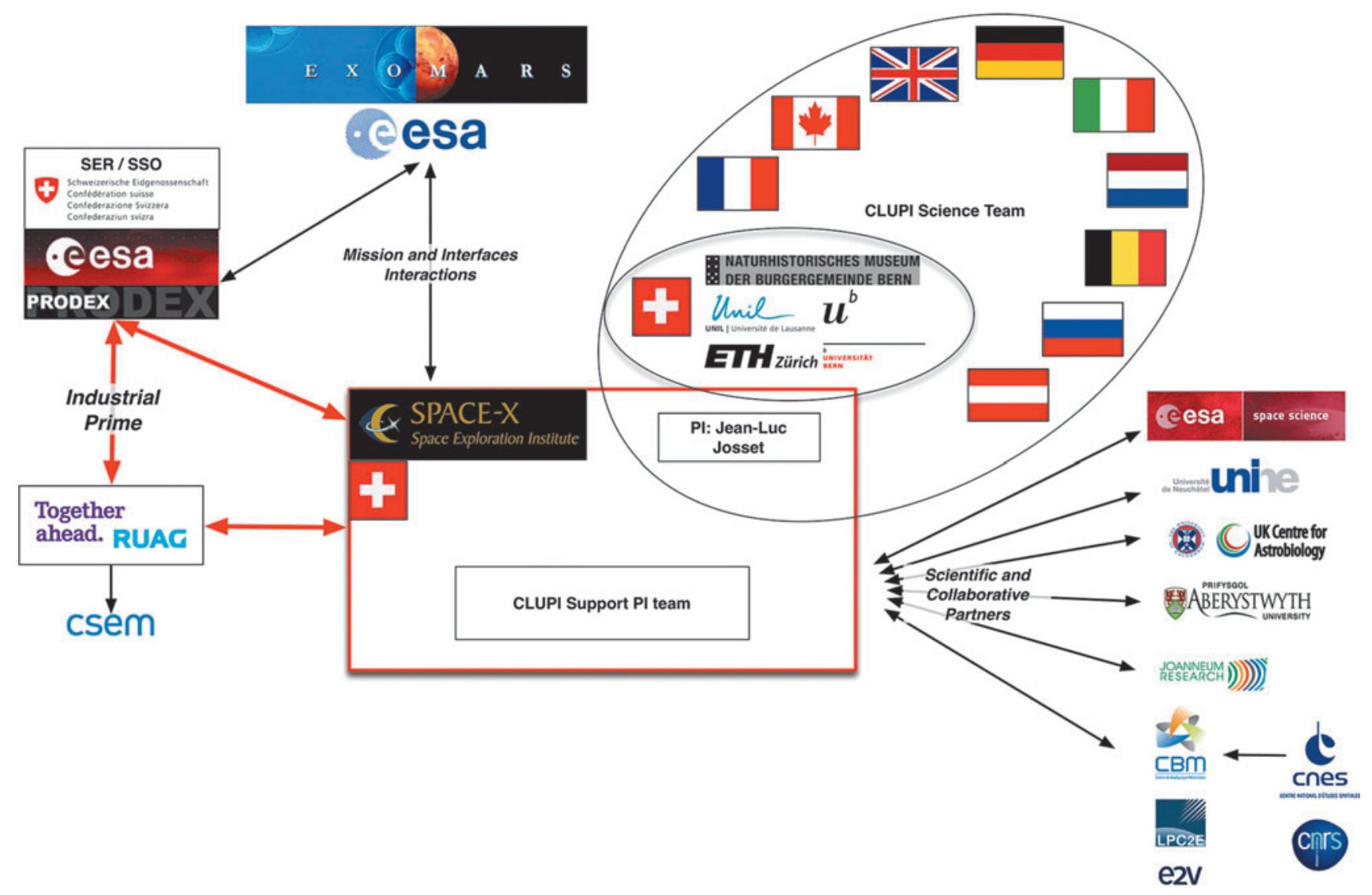

FIG. 1. CLUPI working team organization. CLUPI, close-up imager.

Meridiani Planum. ExoMars 2020 will land an instrumented rover on Mars.

The overall ExoMars objectives are twofold: (i) technology demonstration and (ii) scientific investigations. The technology demonstration comprises the entry, descent, and landing of a payload on the surface of Mars (ExoMars 2016); surface mobility with a rover; access to the subsurface to acquire samples; and sample preparation, distribution, and analysis (ExoMars 2020). The scientific investigations are aimed at the search for signs of past and present life on Mars, the study of how the water and geochemical environments vary with subsurface depth (up to a few meters) (ExoMars 2020), and the analysis of martian atmospheric trace gases and identification of their sources (ExoMars 2016).

The ExoMars Rover has a nominal mission duration of 218 sols (approximately seven Mars months). The rover is equipped with a drill for subsurface sample collection. It also includes the Pasteur suite of instruments: PanCam (panoramic camera; two wide-angle cameras, WACs; and a high-resolution camera, HRC), CLUPI (Close-Up Imager), ISEM (infrared spectrometer for ExoMars), WISDOM (a ground-penetrating radar), ADRON (a neutron detector for determining subsurface hydration), Ma_MISS (Mars Multispectral Imager for Subsurface Studies), MicrOmega (VisIR imaging spectrometer for mineralogy studies), RLS (Raman Laser Spectrometer), and MOMA (Mars Organic Molecule Analyzer).
In this article, we focus on the CLUPI instrument, which is being developed through international and multidisciplinary science and technical teams, as illustrated in Fig. 1. The CLUPI instrument is being developed by a SwissFrench consortium supported by the Swiss Space Office and the French Space Agency CNES under the PI (Principal Investigator) leadership of Jean-Luc Josset with Frances Westall and Beda Hofmann as Co-PIs. The science team consists of scientists from Europe, Canada, and Russia who offer a broad range of expertise, including biosignature recognition, geology, microbiology, and geomorphology, as well as technical aspects related to CLUPI operations.

The following sections describe the CLUPI science objectives and performances, design, and operations, as well as its development status and planned science validation activities.

\section{CLUPI Science Objectives and Performances}

\subsection{Science objectives}

CLUPI is a camera system designed to acquire highresolution, color close-up images of outcrops, rocks, soils, drill fines, and drill core samples. The visual information obtained by CLUPI will be similar to what geologists would obtain by visual observation and by using a hand lens.

CLUPI will acquire images of rock and unconsolidated materials, including dust, regolith, and float rocks (i.e., unattached rocks) with fields of view (FOVs) ranging from 
$1.9 \times 1.3 \mathrm{~cm}$ at $10-\mathrm{cm}$ distance from the target $(7 \mu \mathrm{m} /$ pixel resolution) to, for instance, $104.4 \times 44.4 \mathrm{~cm}$ at $500-\mathrm{cm}$ distance (resolution $394 \mu \mathrm{m} / \mathrm{pixel}$ ) since CLUPI can focus to infinity. These images will provide visual information of structure and texture of the abovementioned materials and, specifically, of in situ rocks to establish rock type, facies, and context stratigraphy in the area of study with the primary aim of interpreting the environment of formation/ deposition of the rocks and thus the potentially habitable paleoenvironment. The CLUPI images will complement those provided by PanCam (Coates et al., 2017), thus giving the all-important detailed context necessary for aiding interpretation of mineralogy and potential visible biosignature, as well as determining drill site location.

In detail, the essential information that CLUPI can provide to interpret rock type and mode of formation includes physical and color characteristics of individual minerals that make up the rocks and textural features related to rock formation. Furthermore, certain morphological biosignatures such as concentrations of organics in biofilms and possible associated (potentially bio-) minerals could also be imaged.

For environmental interpretation, it is important to distinguish primary features from secondary features. The former relate to the original rock and its environment of formation, while the latter are produced by processes acting at a later stage on the rock. The secondary processes may have occurred relatively quickly after formation of the rock (e.g., diagenetic changes to sediments deposited in water or to volcanic rocks extruded into water), during long periods of time through continuous surface alteration (e.g., physical and chemical weathering), or they may occur millions of years later due to major environmental changes and/ or external events (e.g., impacts, later volcanic/hydrothermal events, subsurface fluid migration, mass wasting/erosional phenomena, and all physical and chemical changes affecting rocks as a result of surface alteration, that is, weathering). In fact, surface weathering can sometimes enhance textural/ compositional differences in a rock and thus highlight potential textural biosignatures.
CLUPI color images will be indispensable for identifying visible minerals. While geochemical mineral identification will be made on powdered core samples, thus losing context and original grain shape and size, CLUPI will provide images of the minerals within their original context, enabling the grains to be observed within their matrix, as well as other features of importance for interpreting the nature of a rock and its mode of formation, such as the textural relationship of specific grain types to other types, frequency of occurrence of certain grain types, variability in grain size and shape, and the specific patterns thereof. Individual grains may be identified also by physical properties, such as color, shape, size, sorting, orientation, twinning, cleavage, and luster.

All this information will enable geologists to distinguish, for example, a volcanic rock, such as basalt, from a sedimentary rock, such as a conglomerate formed of basaltic fragments or a sand or siltstone also formed of lithic volcanic fragments. With respect to sediments, the composition of the individual clasts and their textural features are essential for interpreting the mode of formation, such as in situ brecciation, transport by physical mass wasting processes, or by water (rivers, streams, or current flow in larger bodies of water). In this study, especially, grain size, shape, and size distribution allow interpretation of transport mechanisms and their duration. Well-rounded clasts would indicate long transport or deposition in an agitated environment with much grain-to-grain contact and erosion. Angular clasts would indicate deposition close to the source of the clasts. Finergrained sediments may indicate distal deposition, that is, longer transport, or erosion of originally fine-grained friable material. A good example of this kind of textural analysis is the sedimentological study of the conglomerates at Bradbury Rise in Gale Crater on Mars that indicated fluvial transport at the time of deposition $(\sim 3.6 \mathrm{Ga})$ (Williams et al., 2013).

A particularly important objective of CLUPI is the search for morphological features that might potentially indicate biosignatures on outcrops and drill cores. Westall et al. (2015b) concluded that the lack of long-term habitability on Mars, in terms of the continuous presence of water over

FIG. 2. Filamentous fabric consisting of microcrystalline quartz formed by mineralization of filamentous microbes in a cavity of basalt. Ballina, New South Wales, Australia. FOV is $25 \mathrm{~mm}$ (image acquired with CLUPI analog test model). FOV, field of view.

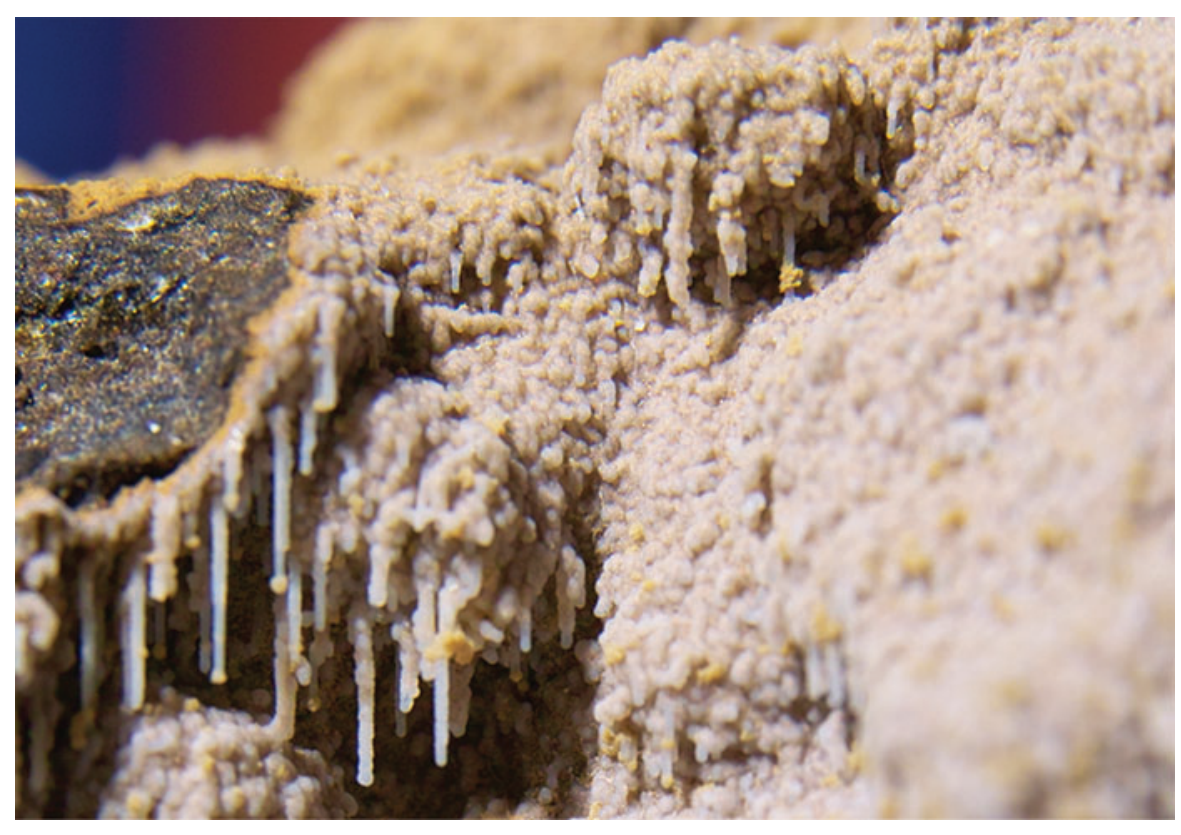


Table 1. Main Characteristics of the Close-Up Imager Instrument

\begin{tabular}{ll}
\hline Specification & \\
\hline Detector type & Full color APS \\
Image dimension & $2652 \times 1768 \times 3$ pixels in color \\
Pixel size & $7.8 \times 7.8 \mu \mathrm{m}$ \\
FOV & $14^{\circ} \pm 2^{\circ}$ diagonal $\left(11.9^{\circ} \times 8.0^{\circ}\right)$ \\
Image resolution/viewed area & $7 \mu \mathrm{m} / \mathrm{pixel}$ at $10-\mathrm{cm}$ distance, viewed area $1.9 \times 1.3 \mathrm{~cm}$ \\
& $39 \mu \mathrm{m} / \mathrm{pixel}$ at 50 -cm distance, viewed area $10 \times 7 \mathrm{~cm}$ \\
& $79 \mu \mathrm{m} / \mathrm{pixel}$ at 100 -cm distance, viewed area $21 \times 14 \mathrm{~cm}$ \\
Working distance & $10 \mathrm{~cm}$ to infinity with variable focus \\
Focal length & Varying to take sharp images from $10 \mathrm{~cm}$ to infinity \\
Quantization & $8-14$ bits \\
Dynamic range & $62 \mathrm{~dB}$ (sensor) quantified on up to 16384 levels $(14$ bits) \\
Electrical interface & SpaceWire on LVDS \\
Exposure time & Up to $1024 \mathrm{~s}$ \\
Spectral range & $400-700 \mathrm{~nm}$ \\
Electronic features & Sequencer, converter, internal buffer, internal clock of $40 \mathrm{MHz}$, \\
& SpaceWire Data Coding \\
Data processing & Automatic exposure time, autofocusing, binning $2 \times 2$ and $4 \times 4$, \\
& $\mathrm{Z}$-stacking (between 2 and 16 images), Windowing \\
Data storage & $4 \mathrm{~Gb}$ \\
Max. mean power consumption & $<15 \mathrm{~W}$ incl. $20 \%$ margin $(25 \mathrm{~W}$ when firing the launch lock) \\
Power lines & $+28 \mathrm{~V}$ \\
Operating temperatures & $-120^{\circ} \mathrm{C}$ to $+30^{\circ} \mathrm{C}$ \\
Storage temperatures & $-120^{\circ} \mathrm{C}$ to $+50^{\circ} \mathrm{C}$ \\
Environment & Compatible with ExoMars Rover 2020 Environment \\
Allocated volume & $170 \times 80 \times 100$ mm \\
Mass of instrument & $932 \mathrm{~g}$ \\
\hline
\end{tabular}

APS $=$ active pixel sensor; FOV $=$ field of view.

periods of millions of years, most likely precluded evolutionary processes leading to the appearance of more sophisticated life forms, such as photosynthesizers. The result would be that life forms on Mars most likely did not have the opportunity to evolve further than the chemotrophic stage. Chemotrophs are microorganisms that do not obtain their energy from sunlight-they use redox couples, including organic and/or inorganic species, and their source of carbon comes either from organic carbon molecules or inorganic carbon, for example, $\mathrm{CO}_{2}$ dissolved in water (e.g., Westall et al., 2015a, 2015b). Traces of such organisms may be preserved as mineralized replacements (microfossils) or
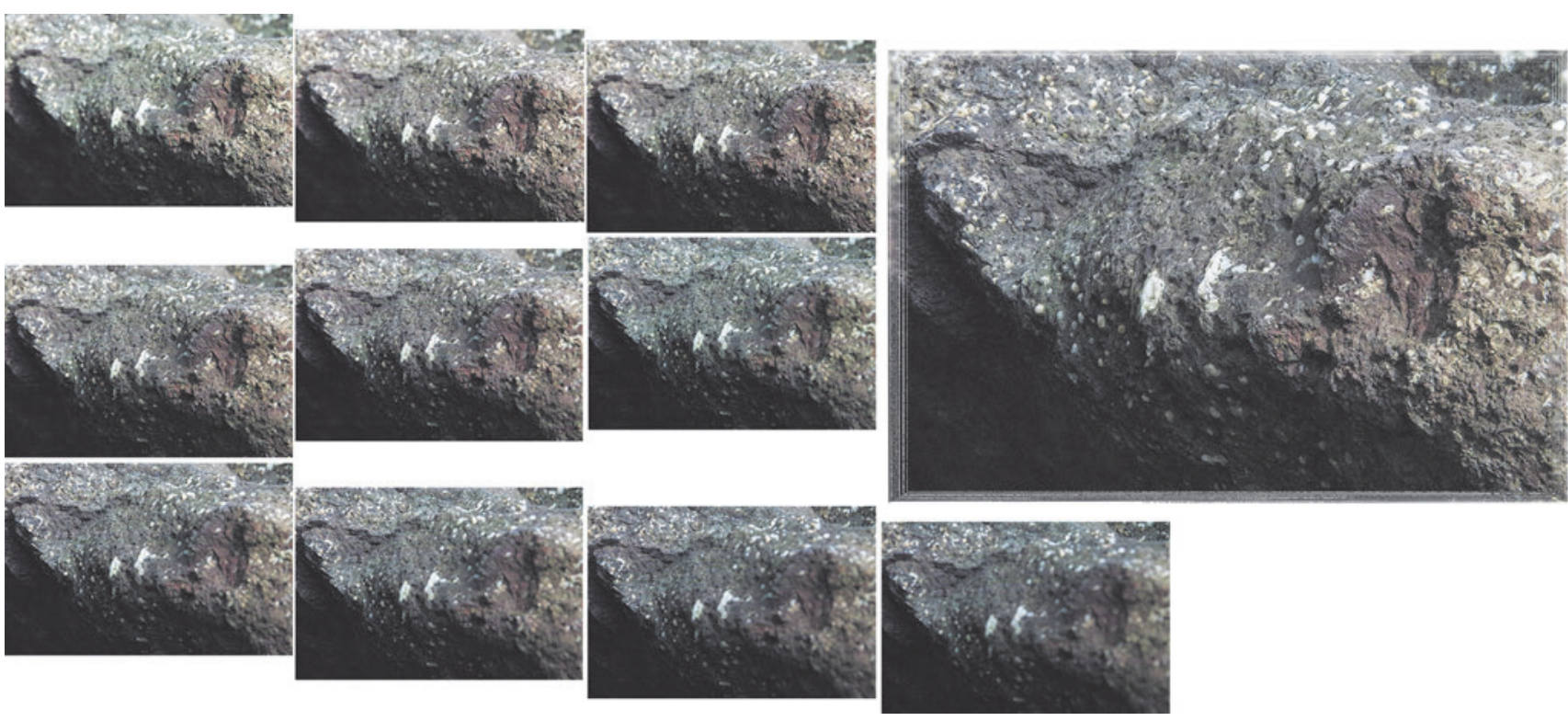

FIG. 3. Illustration of the z-stacking processing: individual images with different sharp areas (small pictures on the left) and the resultant overall sharp image after processing (large picture on the right). The 10 original images were acquired with a CLUPI analog camera during the AMASE 2014 campaign in Tindhólmur, Faroe Islands, at 38-cm working distance, and the processed image (about $10 \mathrm{~cm}$ wide) results from focus stacking experiments by Joanneum Research. 


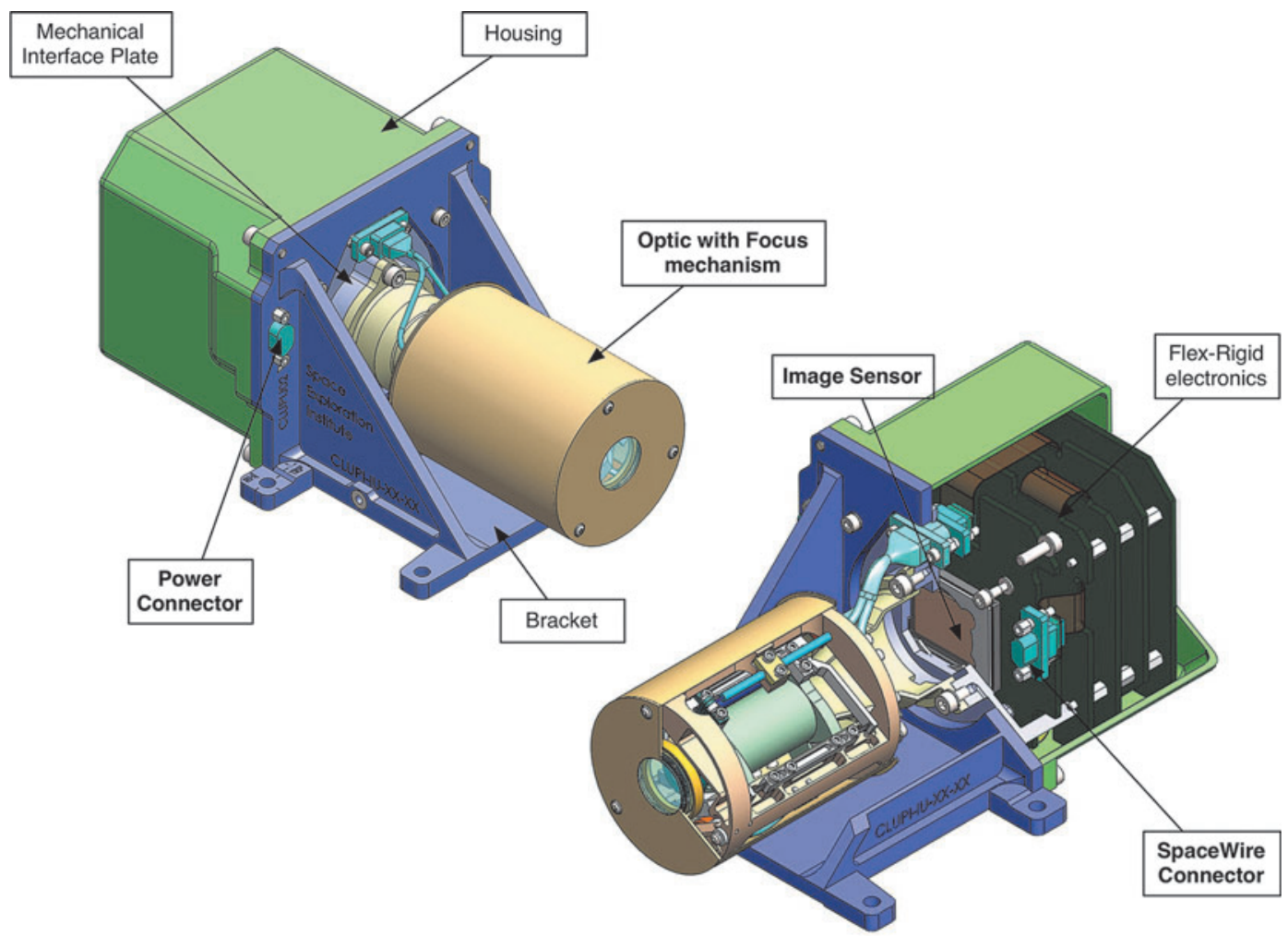

FIG. 4. CLUPI imaging unit (CAD@Space Exploration Institute).

as organic signatures in fine-grained anaerobic sediments or cements (Westall and Cavalazzi, 2011). Comparison can be made with fossilized remains of these kinds of microorganisms in Mars analogue volcanic sediments dating back almost to Noachian $(>3.8 \mathrm{Ga}$ ) and certainly Hesperian $(>3.0 \mathrm{Ga})$ times when life could have emerged and flourished at the surface of the red planet. Fossilized anaerobic chemotrophs are very small, $<1 \mu \mathrm{m}$; occur in colonies up to hundreds of $\mu \mathrm{m}$ in size; and where close to a significant source of nutrients, that is, close to hydrothermal sources, can develop visible carbon-rich (black) biofilms (Westall et al., 2011, 2015a, 2015b). Although CLUPI may not have the capability to observe individual cells, it may be able to distinguish colonies of cells as dark carbonaceous clots and layers of colonies as biofilms. If morphological remains are not visible, but a suggestive organic signature is detected by the laboratory instruments RLS, MicrOmega, or MOMA, the fine-scale context information provided by CLUPI will be essential to interpreting the putative biosignature. Typically, significant sample preparation, such as thin section preparation or etching of the rocks, is necessary to be able to image individual cells or their colonies with an optical microscope or scanning electron microscope. As discussed by Westall et al. (2015b), stromatolites, that is, laminated structures typically associated with the formation of mats produced by the more evolved photosynthesizers, are not likely to be found on Mars. However, mineralized remains of filamentous microbial colonies, typically resulting from the former activity of chemoautotrophs in both surface and subsurface environments, are additional biosignatures that can potentially be identified with CLUPI without any specific sample preparation. Biofabrics of this type are a

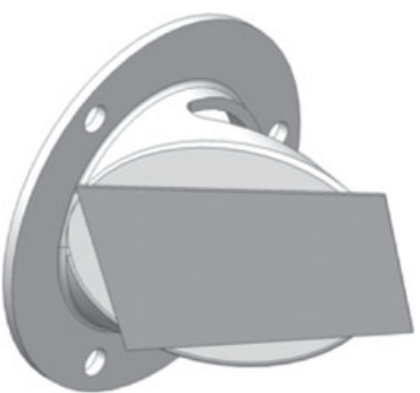

b

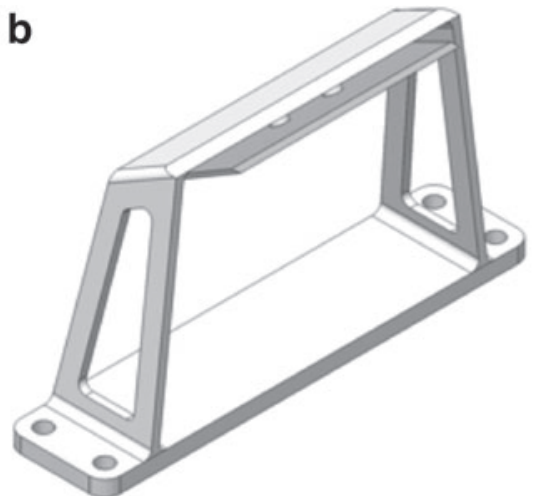

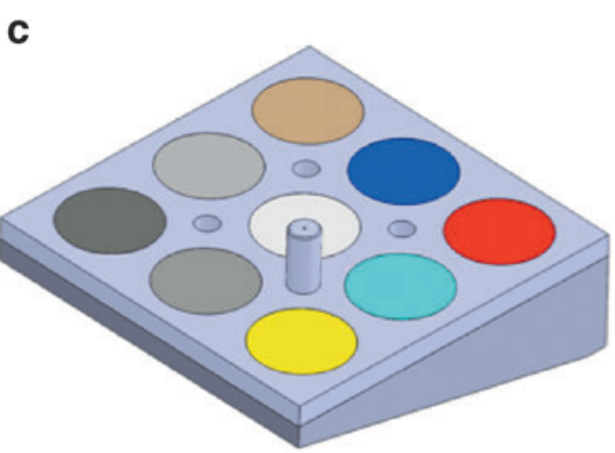

FIG. 5. CLUPI, bracket mirror (a), drill mirror (b), and calibration target (c). 

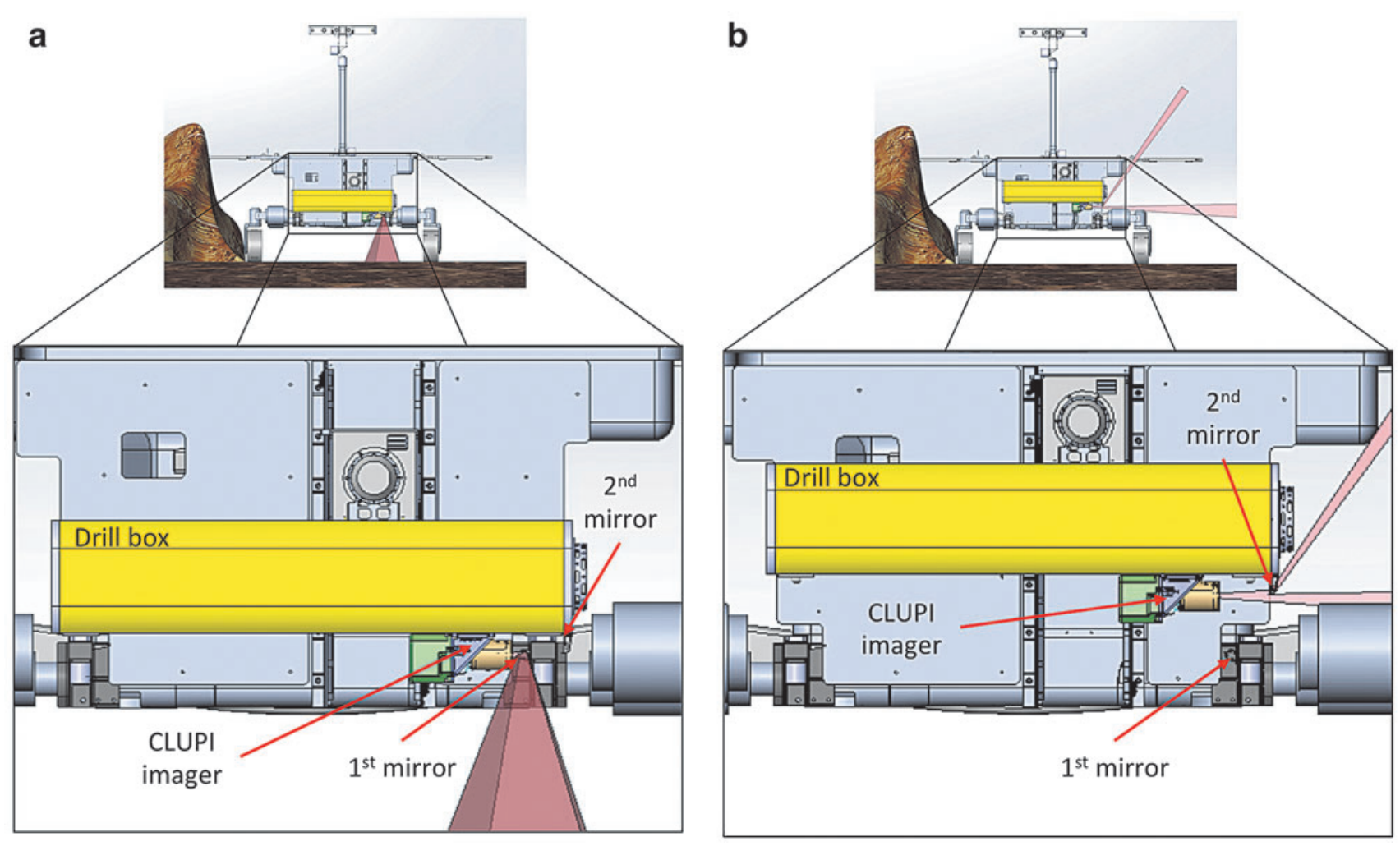

FIG. 6. CLUPI mirror accommodation (the first and second mirrors refer to the bracket mirror and the drill mirror, respectively) with the corresponding FOV when the drill is in stowed position (a) and in nonstowed position (b).
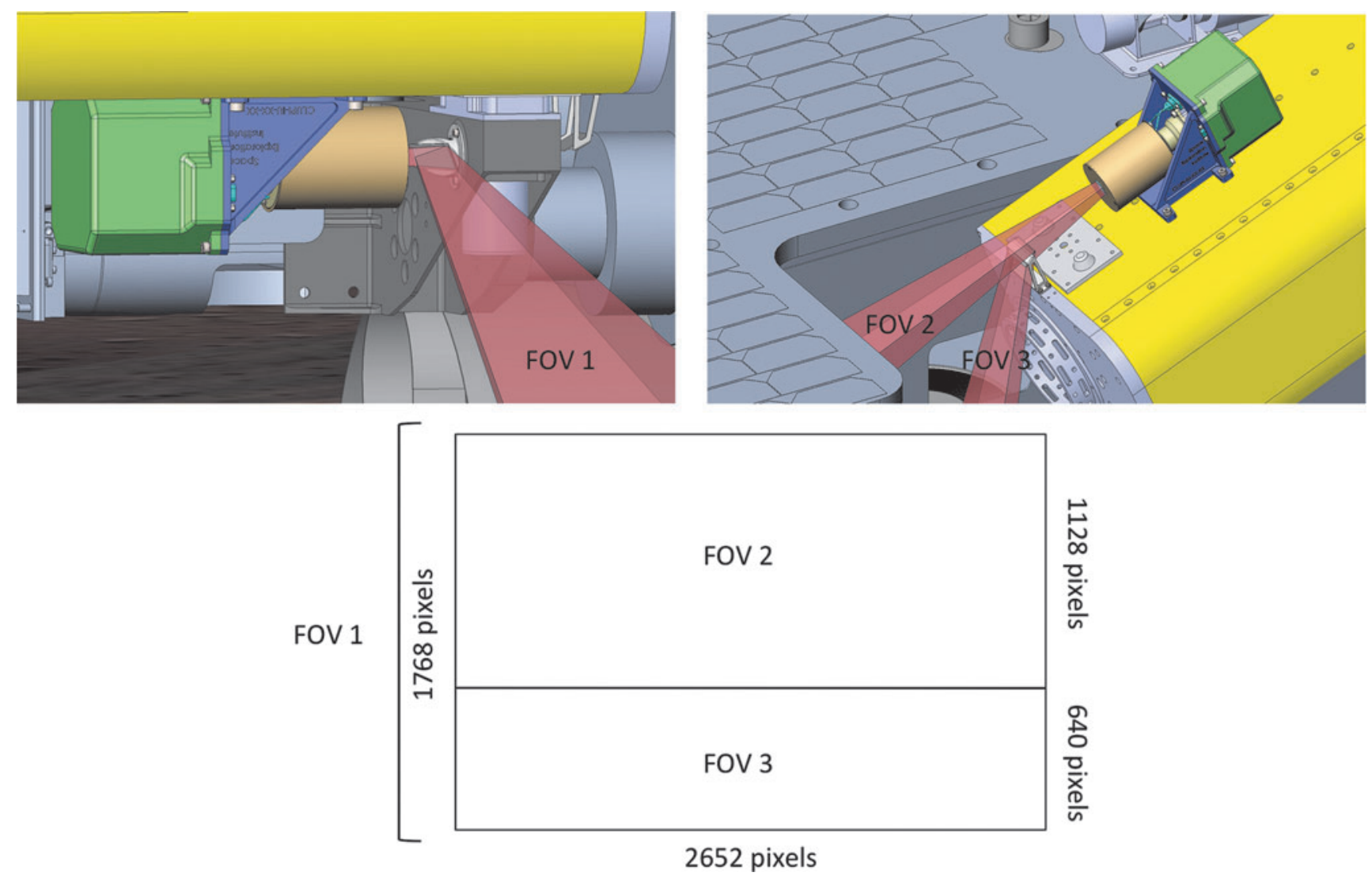

FIG. 7. Definition of the three FOVs of CLUPI. 
observed in various paleoenvironments on Earth (e.g., Fig. 2), both in sedimentary and volcanic settings (Hofmann and Farmer, 2000; Hofmann et al., 2008; Hofmann, 2011; Homann et al., 2016). Moreover, research conducted in caves has shown that stromatolites (sensu lato as laminated structures) and other morphologically complex biogenic structures may also form in the absence of light, confirming the view that other types of microorganisms, apart from photosynthesizers, are capable of producing macroscopic morphological biosignatures (Tisato et al. 2015; Bontognali et al., 2016).

Minerals that are typically produced as a by-product of microbial activity are also commonly produced by abiotic means. On Earth, a myriad of such minerals exist, such as carbonates, oxides, and sulfides (Banfield and Nealson, 1997), but it is difficult to distinguish between their modes of formation without the use of sophisticated observational and analytical techniques (e.g., Thomas-Keprta et al., 2009; Westall et al., 2011). Thus, while CLUPI would be able to identify minerals on the basis of their physical properties as well as make use of the Raman and IR analyses, any interpretation of a biogenic origin could only be made by taking into account other types of potential biosignatures, such as the presence of an organic carbon signature suggestive of microbial fractionation or physical concentrations of carbon suggestive of colonies or biofilms.

In addition to the investigation of morphological features, CLUPI will also have an important role in the study and interpretation of minerals that are not biosignatures per se, but that can be associated with microbial life when found in specific assemblages or sedimentological contexts (Summons et al., 2011). For example, metal sulfides or iron oxides found in association in very low-grade carbon-rich sediments are likely to have a biological origin (Banfield et al., 2001).

In addition to these objectives, CLUPI will provide imagery that will aid the experiments of other instruments, for example, characterization of present-day dust and fines and support for sample extraction and initial handling.

\subsection{Performances}

The camera's requirements (summarized in Table 1) have been selected to maximize the instrument's scientific output. CLUPI is an imager with the ability to focus from $10 \mathrm{~cm}$ to infinity. At a distance of $10 \mathrm{~cm}$ from the target object, the resolution of the images will be high-about $7 \mu \mathrm{m} / \mathrm{pixel}$.
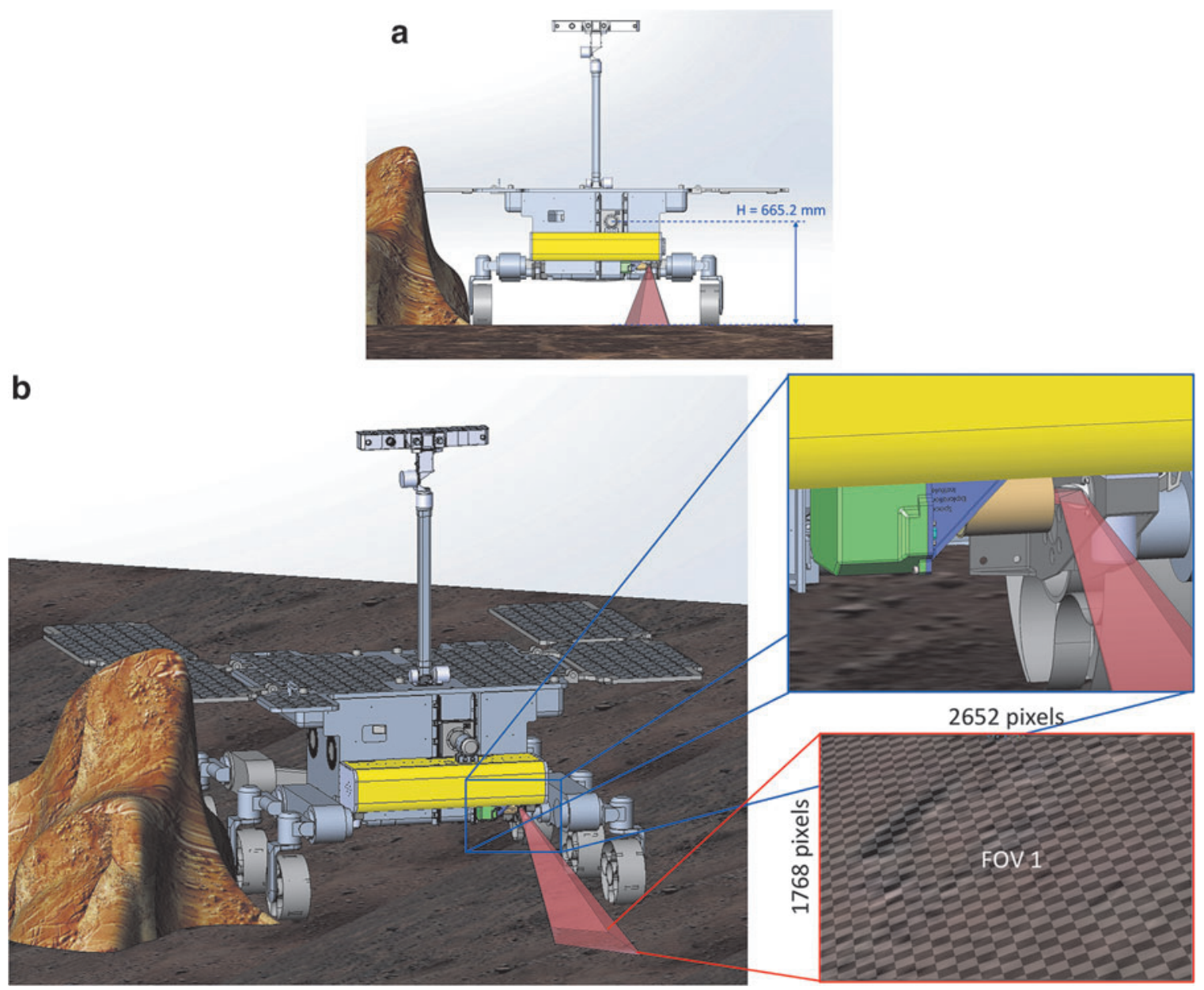

FIG. 8. Drill in stowed position (a) and CLUPI FOV 1 looking at the surface in front of the rover (the tiles are squares of $12.5 \times 12.5 \mathrm{~mm}$ projected on the surface) $(\mathbf{b})$. 
Color imaging is achieved by a detector with three layers of pixels (red, green, and blue).

CLUPI will be able to perform z-stacking (or focus stacking) of images, when necessary, to increase the scientific return. Z-stacking is a processing technique that combines multiple images taken at different focus distances. The portions that are in focus are extracted to create a new composite image that has a greater focal depth than any of the original individual images (illustrated in Fig. 3).

The instrument can also perform autoexposure and autofocus. Furthermore, binning $(2 \times 2$ and $4 \times 4)$ and windowing functionalities allow adapting the data volume to the available communications budget, that is, sending a flexible amount of data.
In the following section, we describe the technical aspects of the instrument in more detail.

\section{CLUPI Instrument Description}

The CLUPI camera is a miniaturized, low-power, efficient, and highly adaptive imaging system having a mass of $932 \mathrm{~g}$, with specific microtechnical innovations regarding its sensor and the focus mechanism.

The CLUPI imaging unit (Fig. 4) is the main element of the instrument. It handles image acquisition and processing. It comprises the optics plus focus mechanism, instrument electronics, and mechanical parts that include the mechanic interface, bracket, and housing. Contrary to detectors that

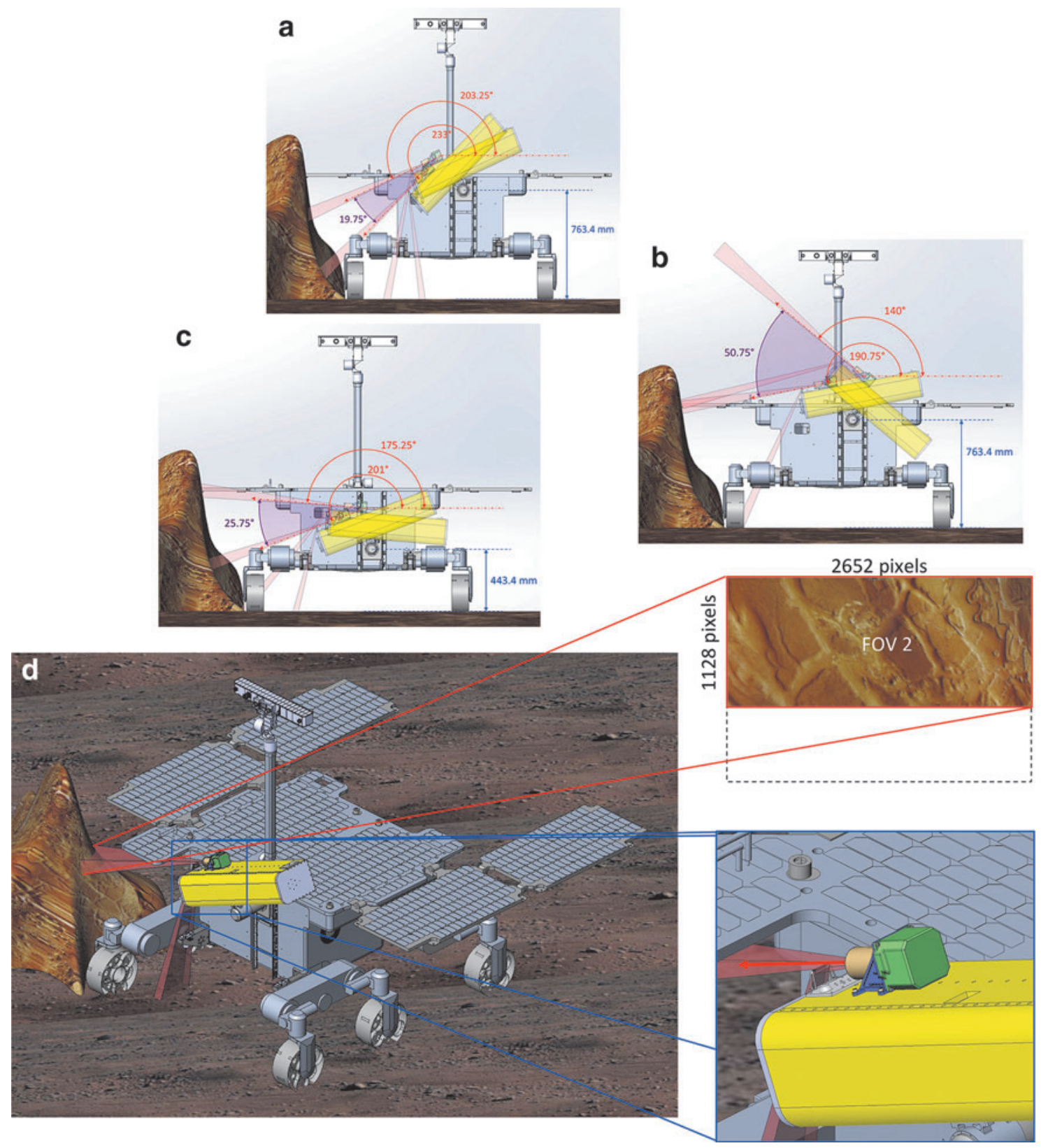

FIG. 9. Drill high (a), (b), and low (c) positions for close-up observation of outcrops, and CLUPI FOV 2 looking at an outcrop on the side of the rover in the nonstowed position $(\mathbf{d})$. 
use a Bayer filter for color acquisition and thus need to merge four pixels (one red, one blue, and two green) to provide color information, the CLUPI sensor is made of three layers of pixels (red, green, and blue) that preserve spatial resolution (each pixel contains the full color information). The focus mechanism is based on flexible structures, so it does not need a stepper motor, lubrication, or gears, and it works without friction.

CLUPI will be accommodated on the drill box of the rover. By using the degrees of freedom provided by both the rover and the drill box, CLUPI will be angled and raised so that it can observe in a variety of viewing modes. The use of two fixed mirrors-one flat and one concave (Fig. 5)—will provide three FOVs.

The first mirror (or bracket mirror), fixed on the rover bracket that holds the drill when in stowed position, gives an image of $2652 \times 1768$ pixels (FOV 1). The second mirror (or drill mirror), fixed on the drill box near the front end of the box, splits the FOV into two parts: (i) the main part, $2652 \times 1128$ pixels (FOV 2), is not deflected and looks in the direction of the optical axis of CLUPI and (ii) the smaller part of the sensor, $2652 \times 640$ pixels (FOV 3), looks toward the drill tip. Figures 6 and 7 illustrate the three FOV and accommodation of CLUPI.
A calibration target (Fig. 5), developed and provided by Aberystwyth University within the framework of a science collaboration agreement with the Space Exploration Institute, is used to color calibrate images during science operations. It is mounted on the right rover bogie bracket, below the drill box, in a position that can be observed by CLUPI (Section 4.7).

\section{CLUPI Scientific Operations during the ExoMars Mission}

To achieve CLUPI objectives and optimize the instrument's science return, science operations and specific related configurations have been designed by the scientific and technical team at the Space Exploration Institute (see CAD illustrations in Figs. 6-14). Both the rover's mobility and the drill's degrees of freedom are taken into account.

\subsection{Geological environment survey}

For the geological survey, CLUPI will observe the area immediately in front of the rover, using one of the fields of view-FOV 1.

This will allow for the characterization of physical properties that include hardness, induration, friability (the latter determined from the texture of the rock, e.g., whether
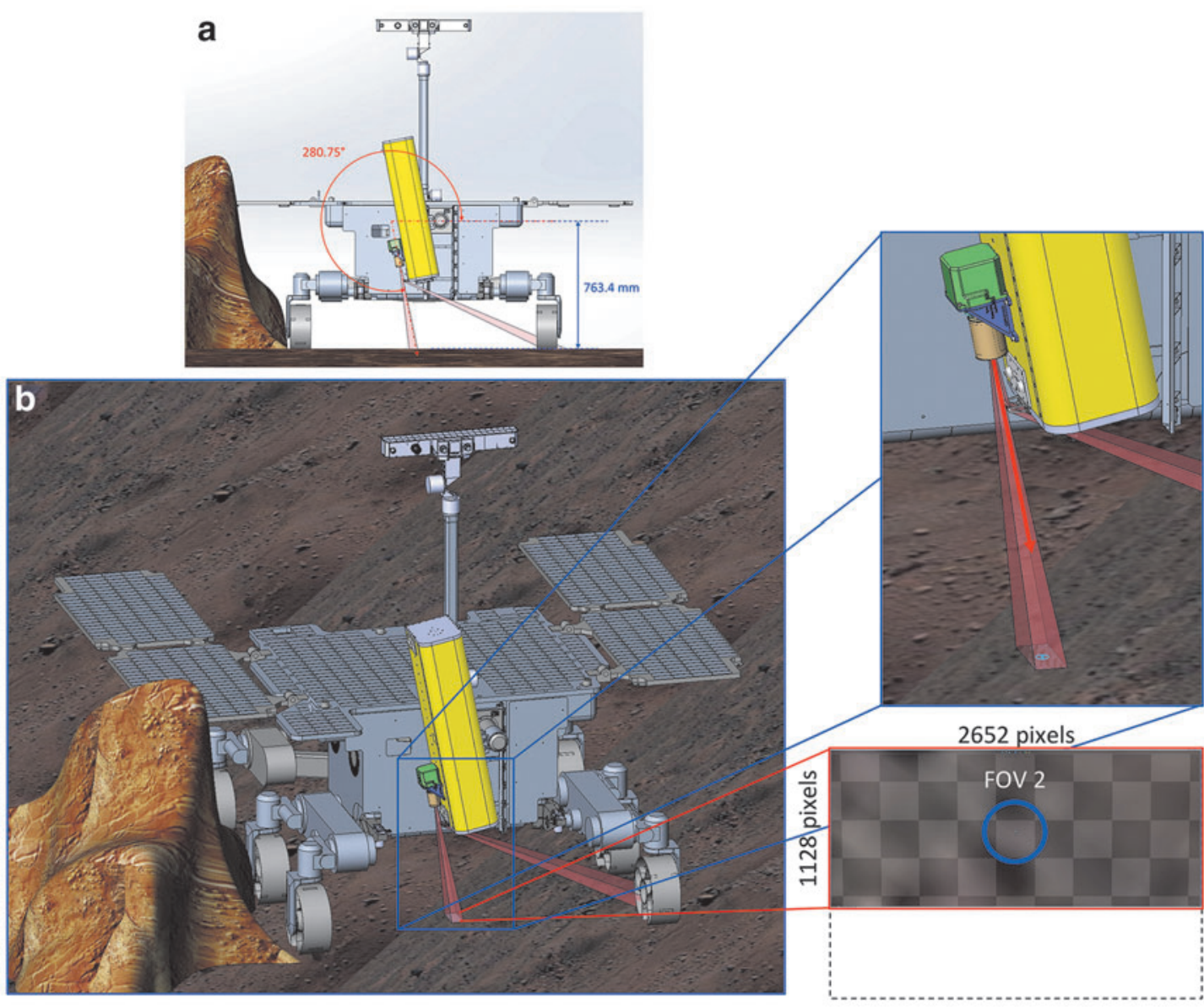

FIG. 10. Drill high position during drilling area observation (a) and corresponding CLUPI FOV 2 (the blue circle, corresponding to the prospective drill hole, is $2 \mathrm{~cm}$ in diameter and tiles are squares of $12.5 \times 12.5 \mathrm{~mm}$ projected on the surface) (b). 

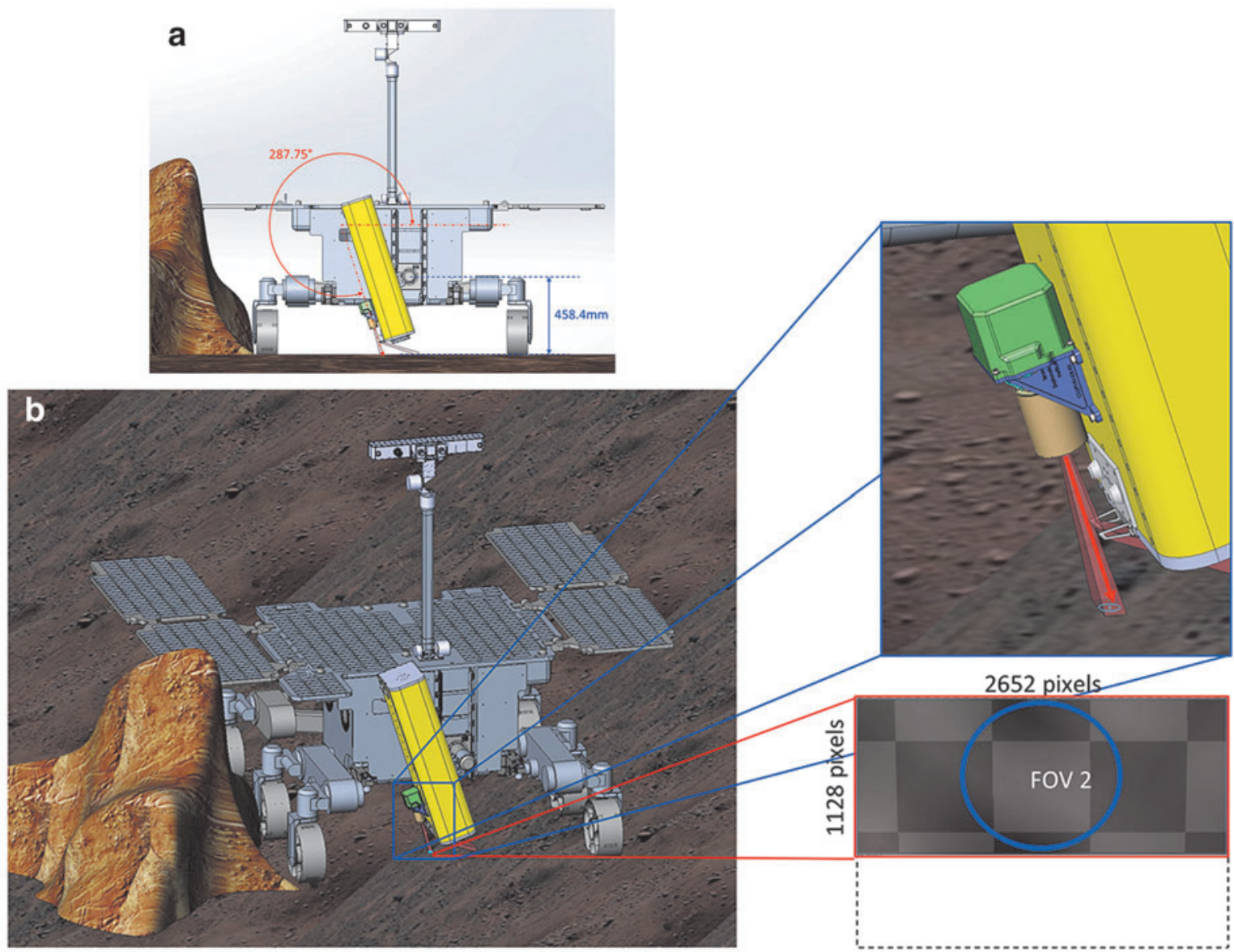

FIG. 11. Drill low position during drilling area observation (a) and corresponding CLUPI FOV 2 (the blue circle, corresponding to the future drill hole, is $2 \mathrm{~cm}$ in diameter and tiles are squares of $12.5 \times 12.5 \mathrm{~mm}$ projected on the surface) (b).

it shows porosity, and from the amount, size, and shape of eroded material deposited below it), morphological features of rocks, such as outcrop structure, and fine-scaled features such as laminae, bedding, fractures, veins, and voids, as well as textures of rocks and regolith and the morphology of surfaces. Texture categories include the following: grain and crystal sizes and their size distribution, grain shapes, grain distribution within a matrix, crystal shapes, and the interrelationship between grains and/or crystals; porosity and vesicularity and their sizes, morphology, and distribution or infilling by secondary minerals; layering and lamination and texture of layers, such as size grading and sorting of grains, ripples, or cracks; and internal texture of grains, such as occurring in ooids. These observations then allow for determination as to whether the rock in question is of volcanic (such as lava, tephra, or ash), aeolian (dune sediments, loess), fluvial (gravel, sands), lacustrine/marine (such as fine-grained and/or laminated chemical deposits), or subterraneous (such as crack fillings) origin or whether it has been deposited as an impact breccia. Only then can critical questions, such as habitability and the possible presence of biosignatures (e.g., biologically induced deposit or a permineralized (fossilized) microbial mat), be discussed.

In this mode, the soil and, in particular, the rover's track marks can also be examined in great detail, thus allowing observation of grain size, soil consistency, and depth of the superficial oxidized layer. This close-up characterization of the surface is complementary to the PanCam WACs, which have a wider FOV, but lower resolution. An excellent synergy exists between the images that can be captured by PanCam and CLUPI. The PanCam WACs provide observations at panoramic (tens of meters to sub-m) scale, while the HRC can acquire more detailed images of relatively large areas. CLUPI allows zooming in and focusing on the critical $\mathrm{cm}$ to sub-mm range of observations. By carefully planning and nesting observations between these two instruments, it is possible to perform a very exhaustive visual examination of interesting targets.

The Geological Environment Survey is performed while the drill is in stowed position, with CLUPI using FOV 1 to look in front of the rover, as illustrated in Fig. 8.

The characteristics of CLUPI images at various working distances for geological environment survey are presented in Table 2.

\subsection{Close-up observation of outcrops}

For close-up outcrop observation, CLUPI will look to the side, using another field of view-FOV 2. In this mode, and by using the rover's motion, CLUPI can be panned across a rock surface to image its structure in 2D and 3D (the latter by making use of highly overlapping images and structure from motion processing techniques). With this observation mode, basic geological information on outcrops is obtained, including rock texture and structure, possible secondary alterations 


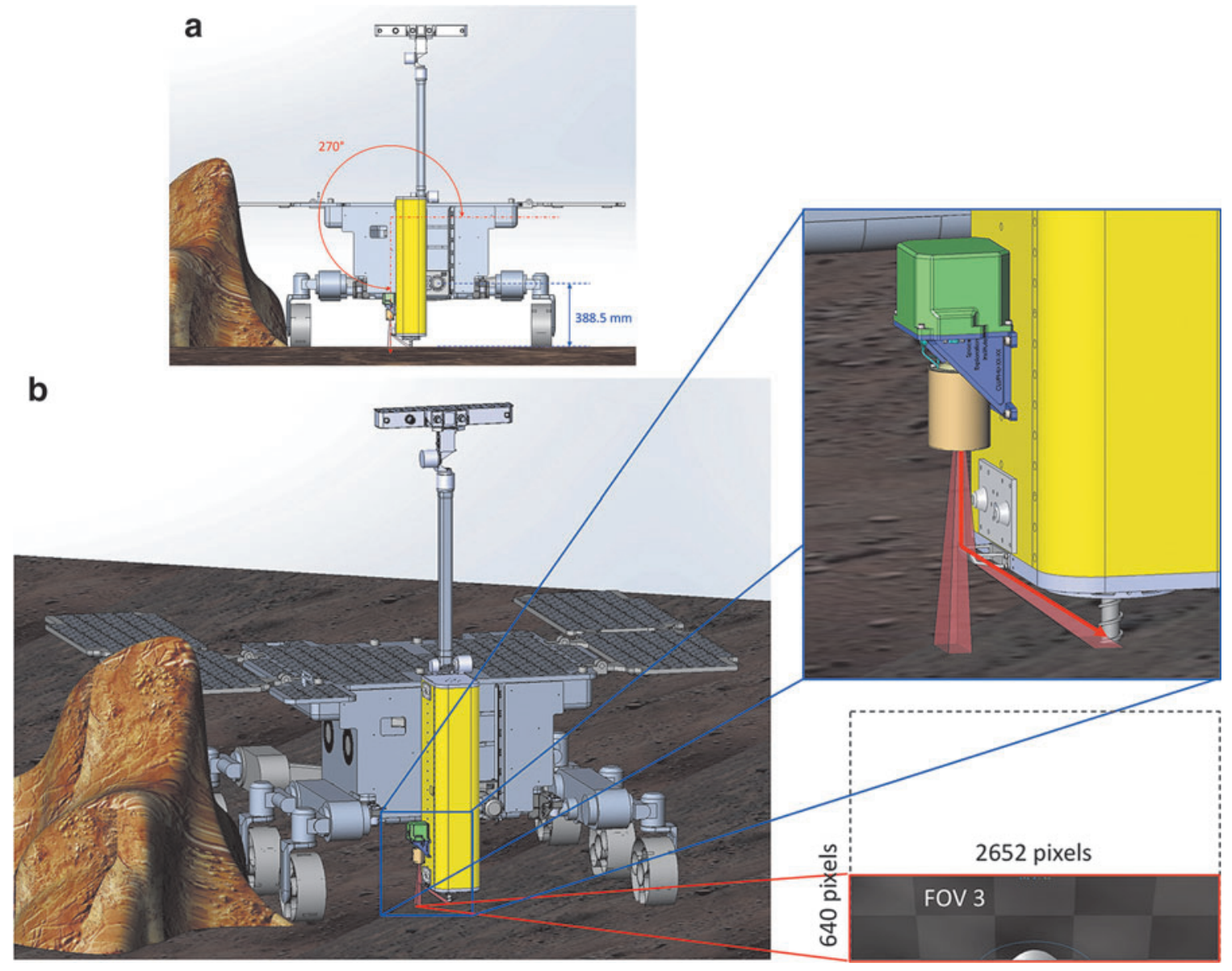

FIG. 12. Drill position during drilling operation observation (a) and CLUPI FOV 3 looking at the fines during the drilling (b).

related to water, and the effects of erosion. This will allow establishing the geological history of targets as well as appraising the potential preservation of biosignatures.

Moreover, imaging of the same target from different working distances (in collaboration with PanCam), and thus at various resolutions, gives access to a multiscale analysis, which can provide information about the target's overall morphology, structure, and texture down to its individual components.

Complementary to PanCam WACs and HRC, CLUPI offers high resolution at close distances and a specific capacity to observe outcrops. The various movements of the rover (forward, backward, turn left and right, sideways, or crabbing) and the two degrees of freedom of the drill when in a nonstowed position $\left(380 \mathrm{~mm}\right.$ vertical movement and $360^{\circ}$ rotation), along with the wide range of working distances of CLUPI, allow imaging a large variety of outcrop configurations with CLUPI FOV 2 at distances from $\sim 65 \mathrm{~cm}$ to infinity (for instance, the working distance in Fig. 9 is $\sim 110 \mathrm{~cm}$ ).

The characteristics of CLUPI images for outcrop observation from various distances are presented in Table 2.

\subsection{Drilling area observation}

While the study of outcrops is an important task for CLUPI, the subsurface deposits are also of primary interest from a scientific point of view, specifically for the analytical instru- ments. Although CLUPI could possibly observe and identify morphological biosignatures on the scale of tens of microns, as noted above, the kinds of organisms expected on Mars (Westall et al., 2015b) may not leave signatures that are morphologically visible. For this reason, the emphasis for biosignature detection on the ExoMars mission is the analysis of organics of potential biological origin. Such molecules are likely to be preserved only in the subsurface, below $1.5 \mathrm{~m}$ in depth (Vago et al., 2017), away from oxidants, ultraviolet light, and cosmic radiation damage. Thus, subsurface samples are favored to test the hypothesis of the existence of life on early Mars.

Once the drilling area has been chosen, using its capacity for high-resolution survey of the geological environment, CLUPI can carry out its characterization before drilling under two configurations using FOV 2.

As the drill box is rotated, CLUPI can either be in a high position (incidence angle of $\sim 11^{\circ}$, Fig. 10) or in a low position (incidence angle of $\sim 18^{\circ}$, Fig. 11). In the low position, it is able to help with the characterization of rocks and structures, such as crystals in igneous rocks, grain size and shape distribution and sorting, fine-scale structure, fracture mineralization, secondary minerals, and soil particles. In the higher position, CLUPI can achieve a wider coverage, although with a somewhat lower resolution.

The characteristics of CLUPI images for the drilling areas from both high and close-up distances are presented in Table 2. 


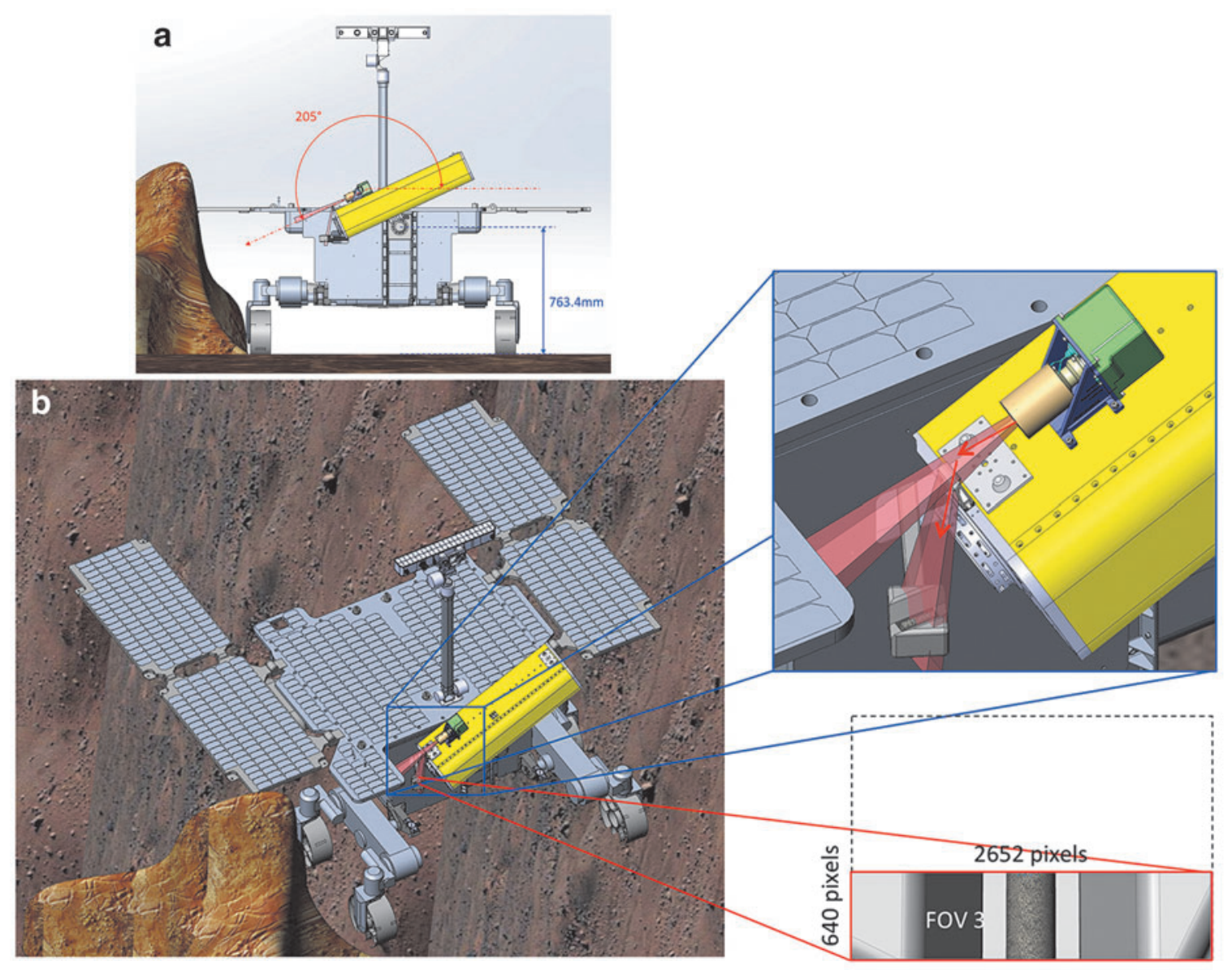

FIG. 13. Drill position for the drilled core sample observations (a) and CLUPI FOV 3 looking at the drilled core sample in the CSTM (b).

\subsection{Drilling operation observation}

Mars missions up to now have penetrated the subsurface to depths of the order of $10 \mathrm{~cm}$. The extraction and analysis of subsurface samples whether from 0.5-, 1-, or 2-m depth have not been attempted so far. These kinds of subsurface samples can provide invaluable information about the subsurface geological composition, especially regarding traces of past life.

While the drilling operation is being performed, the CLUPI third field of view (FOV 3) can be used to monitor the process and observe the mound of fines that is generated. Color and textural variations can be used to infer whether the drill has encountered a different type of material or deposit. FOV 3 can also be used to obtain information on mechanical properties of the soil, such as grain size, shape, and cohesion.

This ability is complementary to that of the Ma_MISS instrument (borehole-side-facing IR spectrometer integrated in the drill rig, De Sanctis et al., 2017). It can also be of use in case a problem arises during drilling (the MAHLI microscope on the Curiosity Rover detected wear on the metal wheels of the rover, thus critically aiding mission operations).

Figure 12 describes the position of the drill for the drilling operation and the CLUPI FOV in such a configuration.

The characteristics of CLUPI images for the drilling operation are presented in Table 2.

\subsection{Observation of the drilled core sample}

Fresh samples from depths in the 0-2 $\mathrm{m}$ range will be collected and analyzed by several instruments after being delivered to the Core Sample Transportation Mechanism (CSTM) - the small open box that extends to receive a sample from the drill. The CLUPI FOV 3 will be used to image the collected core material before delivery to the rover's analytical laboratory for further processing and studies. Whereas the PanCam high-resolution camera can obtain a total view image of the core sample, only CLUPI can image the sample at very high resolution. This will be important for recording sample shape, color, homogeneity, texture, vesicularity, and mineral grain size. This information can then be used to provide essential structural, textural, and eventually compositional data for comparing the core sample with the local and regional environment in the rover sampling area, providing a valuable link between surface and subsurface analyses. Once inside the rover's laboratory, the sample is crushed as only crushed mineral grain assemblages can be observed and analyzed.

The visual examination of the sample (with CLUPI and PanCam) before ingestion and crushing is possible because of the position of the drill after the delivery of the drilled core sample to the CSTM, which allows observation of the drawer's content from above (incidence $7.5^{\circ}$ ) at a distance of about $28.5 \mathrm{~cm}$ using FOV 3 (Fig. 13). 


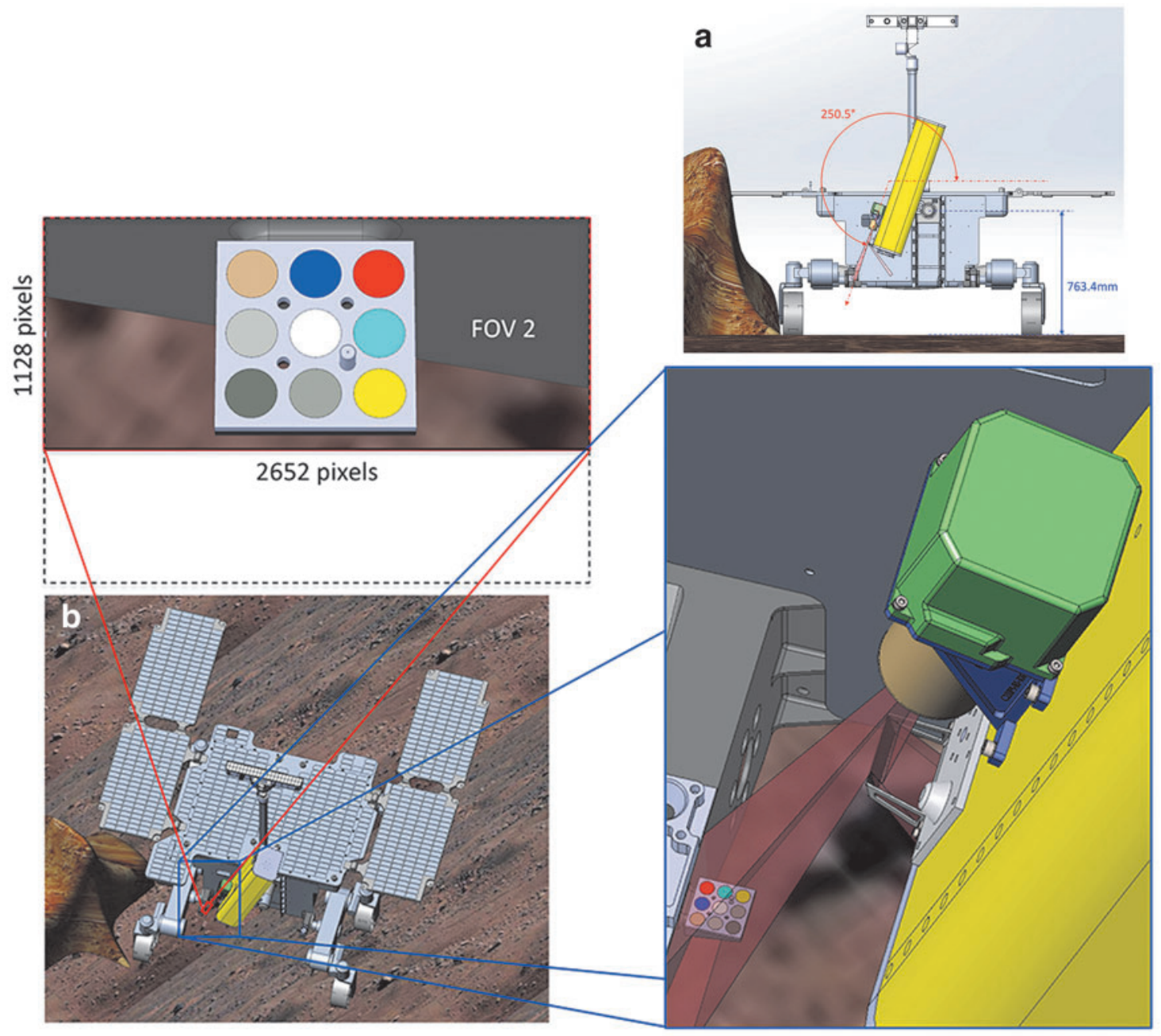

FIG. 14. Drill position during calibration (a), and calibration target for CLUPI in FOV 2 with accommodation on the rover (b).

Table 2. Characteristics of Close-Up Imager Images Under the Different Operation Configurations

\begin{tabular}{lcccc}
\hline Operation & $\begin{array}{c}\text { Working } \\
\text { distance }(\mathrm{cm})\end{array}$ & Viewed area & $\begin{array}{c}\text { Resolution } \\
(\mu \mathrm{m} / \text { pixel })\end{array}$ & $\begin{array}{c}\text { Depth of } \\
\text { Field }(\mathrm{cm})\end{array}$ \\
\hline Geological environment survey & 10 & $1.9 \times 1.3 \mathrm{~cm}(2652 \times 1768$ pixels $)$ & 7 & 0.12 \\
& 50 & $10.4 \times 7.0 \mathrm{~cm}(2652 \times 1768$ pixels $)$ & 39 & 1.6 \\
& 100 & $20.9 \times 13.9 \mathrm{~cm}(2652 \times 1768$ pixels $)$ & 79 & 5.9 \\
Close-up outcrop observation & 111 & $23.2 \times 15.4 \mathrm{~cm}(2652 \times 1768$ pixels $)$ & 87 & 7.1 \\
& 65 & $13.6 \times 5.8 \mathrm{~cm}(2652 \times 1128$ pixels $)$ & 51 & 2.7 \\
& 85 & $17.7 \times 7.5 \mathrm{~cm}(2652 \times 1128$ pixels $)$ & 67 & 4.4 \\
& 110 & $23.0 \times 9.8 \mathrm{~cm}(2652 \times 1128$ pixels $)$ & 87 & 7.1 \\
Drilling area/drill hole observation & 155 & $32.4 \times 13.8 \mathrm{~cm}(2652 \times 1128$ pixels $)$ & 122 & 13.7 \\
& 200 & $41.7 \times 17.8 \mathrm{~cm}(2652 \times 1128$ pixels $)$ & 157 & 22.5 \\
Drilling operation observation & 500 & $104.4 \times 44.4 \mathrm{~cm}(2652 \times 1128$ pixels $)$ & 394 & 135 \\
Drilled core sample observation & 50 & $10.4 \times 4.4 \mathrm{~cm}(2652 \times 1128$ pixels $)$ & 39 & 1.6 \\
Calibration & 26.5 & $3.4 \times 1.5 \mathrm{~cm}(2652 \times 1128$ pixels $)$ & 13 & 0.25 \\
& 28.5 & $5.0 \times 3 \mathrm{~cm}(2652 \times 640$ pixels $)$ & 19 & 0.4 \\
& 26.5 & $5.9 \times 3.2 \mathrm{~cm}(2652 \times 640$ pixels $)$ & 22 & 0.6 \\
\hline
\end{tabular}


The characteristics of imaged drilled samples in the CSTM with CLUPI are presented in Table 2.

\subsection{Observation of the drill hole (and deposited fines)}

Once the drilling operations have been completed and the sample has been delivered, the CLUPI FOV 2 can be used to image the state of the surface after drilling, the amount of dislodged fines, and their color and physical properties.

Drill hole observations can be performed with the drill resuming the same tilted position for imaging the sampling area before drilling (Section 4.3), from both high and low positions (Figs. 10 and 11). With an optimal solar illumination angle (ideally with light shining vertically into the hole, although the drill itself may cause some shadowing, and depending on the mound of fines, it may be possible to observe the walls to some depth within the hole (up to $10 \mathrm{~cm}$ deep from the high position, and up to $6 \mathrm{~cm}$ deep from the low position), which would add significant information on the first centimeters of subsurface layering, given that the drilled core sample will come from a greater depth than what can be observed with CLUPI.

The characteristics of CLUPI images for the drill hole from both high and close-up distances are presented in Table 2.

\subsection{In situ calibration}

In situ calibration is performed by acquiring an image of the calibration target, ideally at least once per operational

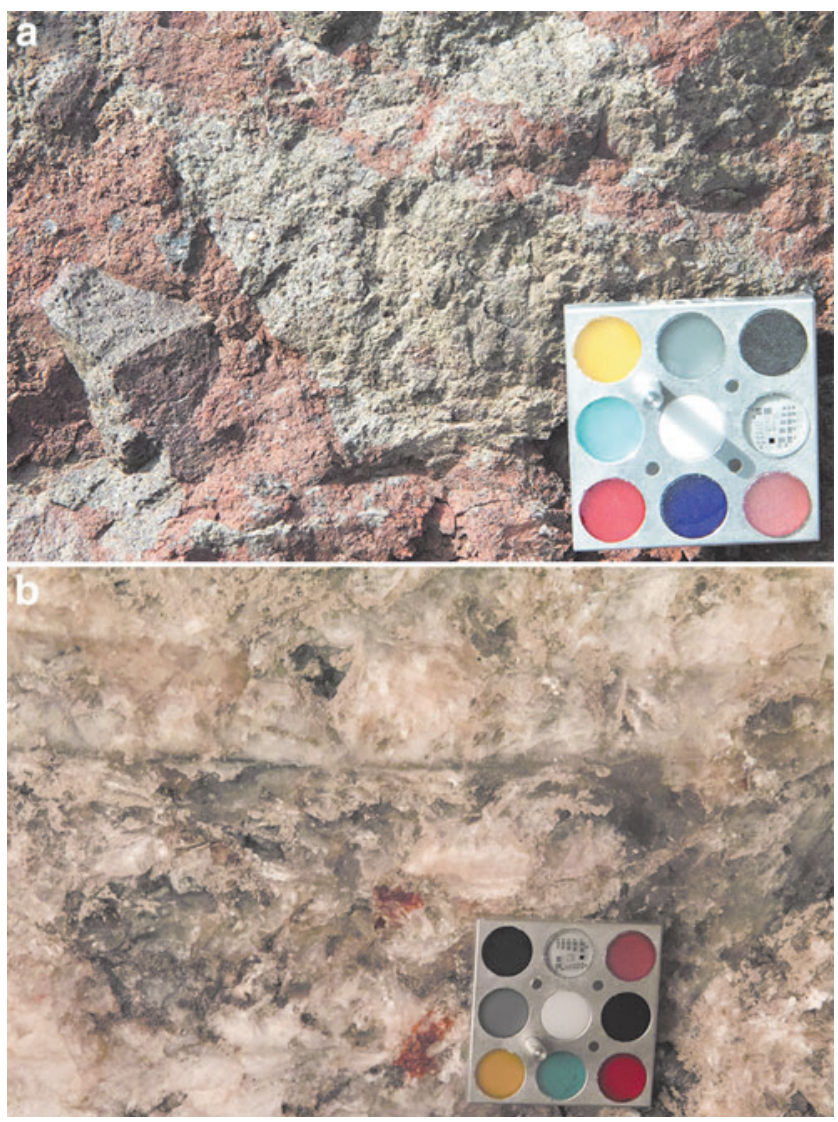

FIG. 15. Examples of pictures with the CLUPI calibration target prototype $(2.5 \times 2.5 \mathrm{~cm})$ during the AMASE 2014 campaign (a) and MINAR III (b). sequence. The calibration target consists of nine $6.5-\mathrm{mm}$ diameter glass color patches with their surfaces processed to obtain uniform diffuse reflectance. The absolute spectral reflectance and Bidirectional Reflectance Distribution Function (BRDF) of each color patch will be accurately determined as part of the prelaunch calibration. The color observed by CLUPI on Mars, in combination with knowledge of the relative illumination angle, which can be determined from the shadow post, will allow CLUPI data to be calibrated to provide true color images and accurate reflectance measurements. During the mission, the CLUPI
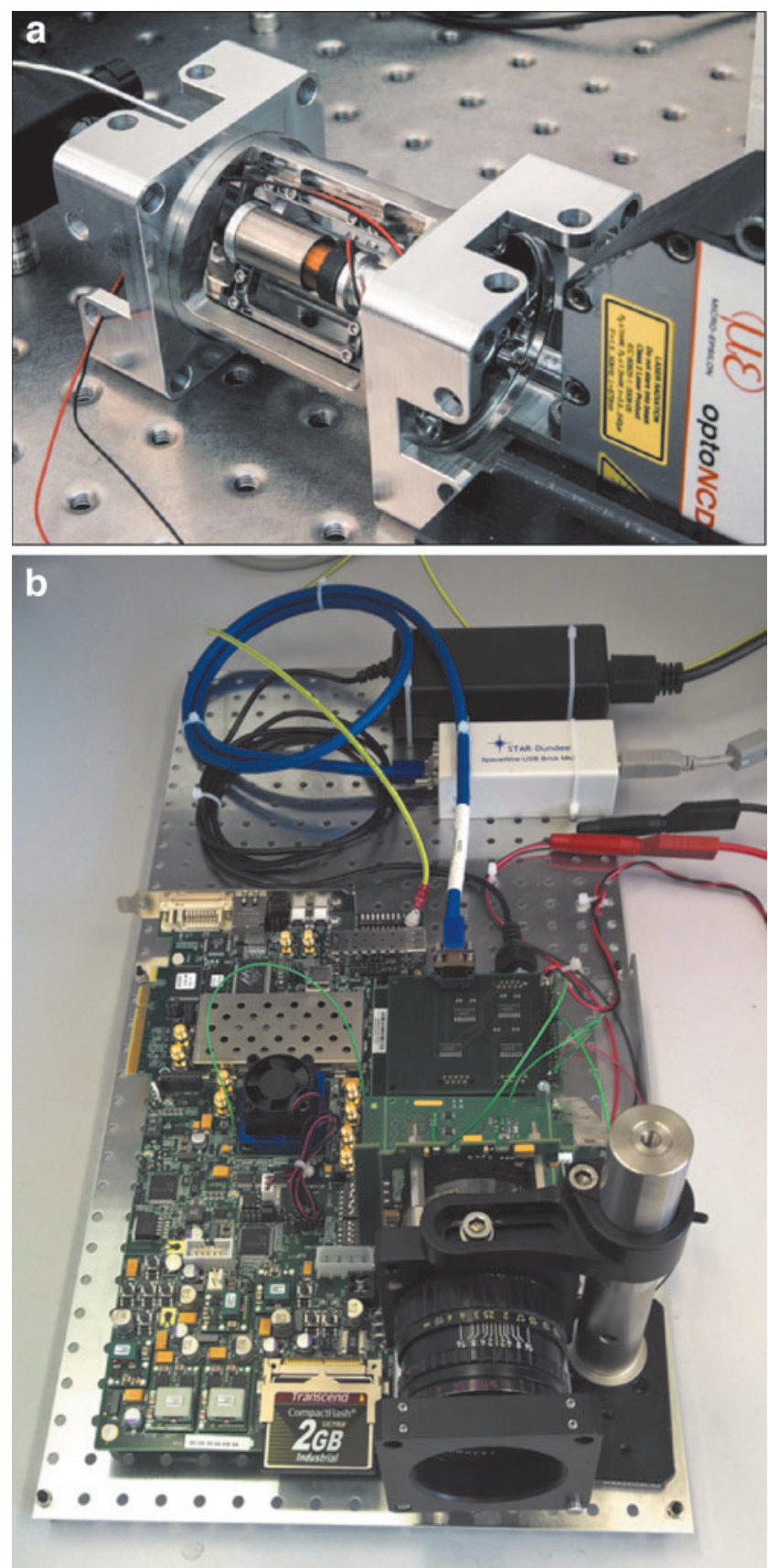

FIG. 16. CLUPI focus mechanism breadboard developed and assembled at the Space Exploration Institute (a) and focal plane assembly breadboard (b) developed by RUAG Space. 
calibration target will be protected from the worst of the martian aeolian dust by the drill box and so is not expected to become contaminated to the same extent as other calibration targets accommodated on the rover's deck, such as PanCam's. Low levels of dust contamination can be compensated for with numerical models.

The calibration target will be located and observed as described in Fig. 14. Its surface is $25 \times 25 \mathrm{~mm}$, the height of the shadow post is $4.1 \mathrm{~mm}$, and it has a mass of $4.5 \mathrm{~g}$. CLUPI imaging of the calibration target will take place at an incidence angle of $19.5^{\circ}$.

The characteristics of CLUPI images for the calibration operation are presented in Table 2 .

\section{Development Status and Planned Science Validation Activities}

An important part of an instrument development is its calibration as well as the science validation activities. During phase B of CLUPI development, a CLUPI analog instrument (same detector as the flight model) was used on several Mars analog field campaigns, including AMASE (Arctic Mars Analogue Svalbard Expedition) in 2009, 2010 (e.g., Steele et al., 2011), 2011, 2013, and 2014 (the latest expedition having been in the Faroe Islands, e.g., Amundsen et al., 2016); SAFER (Sample Acquisition Field Experiment with a Rover) in 2013; and MINAR II and III in 2014 (Josset et al., 2014; Payler et al., 2017). The CLUPI calibration target prototype (manufactured by Aberystwyth University) has been used during several field test campaigns (Fig. 15). Laboratory science validation activities have also been performed (Bost et al., 2015).

The phase C/D of the CLUPI development started in July 2015. A control loop through simulation for the focus mechanism is currently being developed, and a focal plane assembly is being tested at the Space Exploration Institute (Fig. 16).

Planned activities with the next models include calibration (dark current, light transfer/linearity, flat fielding, cosmetic defects, distortion, detector color calibration) and characterization (FOV, spatial resolution, and depth of field), as well as testing of the implemented functionalities (autoexposure, autofocus, binning, windowing, and z-stacking).

Training and rehearsal of CLUPI operations (Section 4) will also be performed under controlled lighting conditions and employ a geometric drill simulator (scale 1:1 to the ExoMars 2020 Rover; Fig. 17) for realistic geometrical configurations.

A specific project designed to use CLUPI images for identification of rocks by using the powder generated by the drill is also under discussion in collaboration with the French Centre de Biophysique Moléculaire (Co-PI and Coinvestigator partnership).
FIG. 17. Geometric drill simulator corresponding to the ExoMars 2020 Rover mission (scale 1:1) built at the Space Exploration Institute premises.

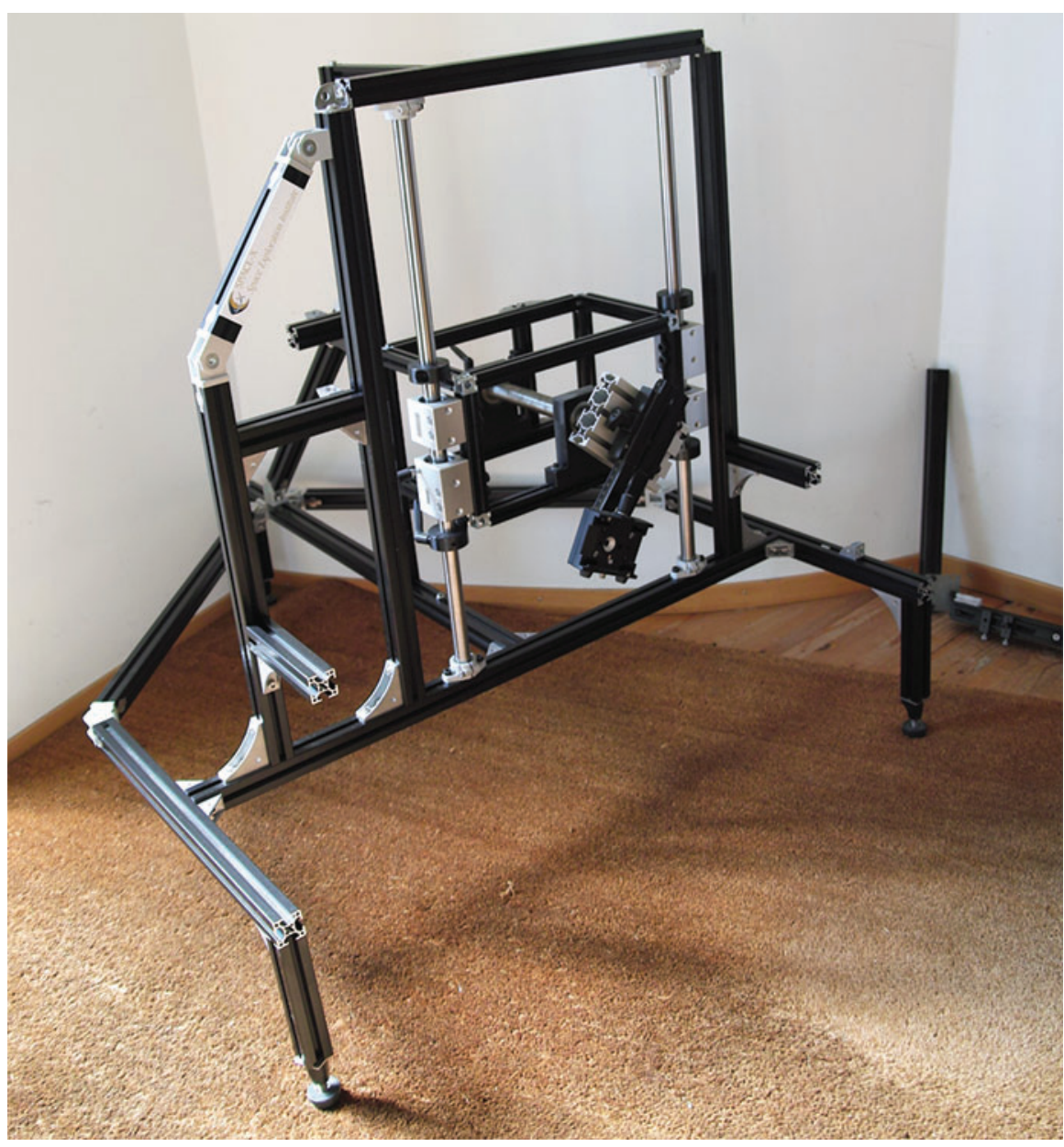


The CLUPI team is also working with the Rover Operation Control Centre (ROCC), and future training and rehearsals of the camera's operations are planned.

\section{Conclusion}

The CLUPI instrument onboard the ESA ExoMars Rover is a powerful miniaturized camera capable of providing high-resolution close-up images in color of rocks, outcrops, drill fines, and drill core samples in an autonomous and flexible way. CLUPI possesses many inbuilt functionalities, such as autofocus, autoexposure, binning, windowing, and z-stacking, all of which can be used to ensure high-quality images and adapt the data output to the available resources the rover can handle during a particular observation cycle (e.g., memory space, uplink rate). CLUPI implementation and operation make the best possible use of the rover and drill motion capabilities. The instrument is able to acquire images in several configurations, achieving a large observational flexibility. CLUPI images will provide essential highresolution complementarity to visual information obtained by PanCam and other instruments in the Pasteur payload.

CLUPI development entered phase C/D in July 2015, and calibration and science validation activities are ongoing, both in field test campaigns and in the laboratory.

\section{Acknowledgments}

The CLUPI team acknowledges the support of the Swiss Space Office and ESA PRODEX Office and the contribution from the French Space Agency, CNES.

\section{Author Disclosure Statement}

No competing financial interests exist.

\section{References}

Amundsen, H.E.F., Árting, U., Bauer, A., Harris, J., Madsen, T., Sansano Caramazana, A., Riishuus, M.S., Schmitz, N., Souchon, A., and Storvik, K.O. (2016) A dissected central volcano at Bíggjarskor, Faroe Islands. $32^{\text {nd }}$ Nordic Geological Winter Meeting, Helsinki.

Banfield, J.F. and Nealson, K.H. (eds.) (1997) Geomicrobiology: Interactions between Microbes and Minerals. Reviews in Mineralogy (Washington, DC: Min. Soc. Am.) Vol. 35, 448 pp.

Banfield, J.F., Moreau, J.W., Chan, C.S., Welch, S.A., and Little, B. (2001) Mineralogical biosignatures and the search for life on Mars. Astrobiology 1:447-465.

Bontognali, T., D’Angeli, I.M., Tisato, N., Vasconcelos, C., Bernasconi, S.M., Gonzales, E.R., and De Waele, J. (2016) Mushroom speleothems: stromatolites that formed in the absence of phototrophs. Front Earth Sci 4:49.

Bost, N., Ramboz, C., LeBreton, N., Foucher, F., Lopez-Reyes, G., De Angelis, S., Josset, M., Venegas, G., Sanz-Arranz, A., Rull, F., Medina, J., Josset, J.-L., Souchon, A., Ammannito, E., De Sanctis, M.C., Di Iorio, T., Carli, C., Vago, J.L., and Westall, F. (2015) Testing the ability of the ExoMars 2018 payload to document geological context and potential habitability on Mars. Planet Space Sci 108:87-97.

Coates, A.J., Jaumann, R., Griffiths, A.D., Leff, C.E., Schmitz, N., Josset, J.-L., Paar, G., Gunn, M., Hauber, E., Cousins, C.R., Cross, R.E., Grindrod, P., Bridges, J.C., Balme, M., Gupta, S., Crawford, I.A., Irwin, P., Stabbins, R., Tirsch, D.,
Vago, J.L., Theodorou, T., Caballo-Perucha, M., Osinski, G.R., and the PanCam Team. (2017) The PanCam Instrument for the ExoMars Rover. Astrobiology 17:511-541.

De Sanctis, M.C., Altieri, F., Ammannito, E., Biondi, D., De Angelis, S., Meini, M., Mondello, G., Novi, S., Paolinetti, R., Soldani, M., Mugnuolo, R., Pirrotta, S., Vago, J.L., and the Ma_MISS Team. (2017) Ma_MISS on ExoMars: mineralogical characterization of the martian subsurface. Astrobiology 17:612-620.

Hofmann, B. (2011) Subsurface filamentous fabrics. In Encyclopedia of Geobiology, edited by V. Thiel and J. Reitner, Springer, Berlin, pp. 851-853.

Hofmann, B.A., and Farmer, J. D. (2000) Filamentous fabrics in low-temperature mineral assemblages: are they fossil biomarkers? Implications for the search for a subsurface fossil record on the early Earth and Mars. Planet Space Sci 48: 1077-1086.

Hofmann, B.A., Farmer, J.D., von Blanckenburg, F., and Fallick, A.E. (2008) Subsurface filamentous fabrics: an evaluation of possible modes of origins based on morphological and geochemical criteria, with implications for exoplaeontology. Astrobiology 8:87-117.

Homann, M., Heubeck, C., Bontognali, T.R., Bouvier, A.S., Baumgartner, L.P., and Airo, A. (2016) Evidence for cavity-dwelling microbial life in 3.22 Ga tidal deposits. Geology 44:51-54.

Josset, J.-L., Souchon, A., Josset, M., and Cockell, C. (2014) ExoMars CLUPI Instrument Testing at MINAR II. European Planetary Science Congress Vol. 9, EPSC2014-658.

Payler, S.J., Biddle, J.F., Cousins, C.R., Cross, R.E., Cullen, D.C., Downs, M.T., Direito, S., Edwards, T., Edwards, P.H., Gray, A.L., Genis, J., Gunn, M., Hansford, G.M., Harkness, P., Harris, L.V., Holt, J., Hutchinson, I.B., Ingley, R., Josset, J.-L., Li, X., Lees, D.S., Lim, D.S., Malherbe, C., McHugh, M., McLuckie, D., Paling, S.M., Souchon, A., and Cockell, C.S. (2017) Planetary Science and Exploration in the Deep Subsurface: results from the MINAR Program, Boulby Mine, UK. Int J Astrobiology 16(2):114-129.

Steele, A., Amundsen, H.E.F., Fogel, M., Benning, L., Schmitz, N., Conrad, P., Younse, P., and Backes, P.; the AMASE 2010 Team. (2011) The Artic Mars Analogue Svalbard Expedition (AMASE) 2010 [abstract 1588]. In $42^{\text {nd }}$ Lunar and Planetary Science Conference, Houston.

Summons, R.E., Amend, J.P., Bish, D., Buick, R., Cody, G.D., Des Marais, D.J., Dromart, G., Eigenbrode, J.L., Knoll, A.H., and Sumner, D.Y. (2011) Preservation of martian organic and environmental records: final report of the Mars Biosignature Working Group. Astrobiology 11:157-181.

Thomas-Keprta, K.L., Clemett, S.J., McKay, D.S., Gibson, E.K., and Wentworth, S.J. (2009) Origins of magnetite nanocrystals in Martian meteorite ALH84001. Geochim Cosmochim Acta 73:6631-6677.

Tisato, N., Torriani, S.F., Monteux, S., Sauro, F., De Waele, J., Tavagna, M.L., D’Angeli, I.M., Chailloux, D., Renda, M., Eglinton, T.I., and Bontognali, T.R.R. (2015) Microbial mediation of complex subterranean mineral structures. Sci Rep 5:1-10. doi: 10.1038/srep15525.

Vago, J., Witasse, O. Baglioni, P., Haldemann, A., Gianfiglio, G., Blancquaert, T., McCoy, D., and de Groot, R., and the ExoMars team. (2013) ExoMars ESA's next step in Mars exploration. ESA Bull 155:12-23.

Vago, J.L., Westall, F., Pasteur Instrument Teams, Landing Site Selection Working Group, and Other Contributors. (2017) Habitability on early Mars and the search for biosignatures with the ExoMars Rover. Astrobiology 17:471-510. 
Westall, F., and Cavalazzi, B. (2011) Biosignatures in rocks. In Encyclopedia of Geobiology, edited by V. Thiel and J. Reitner, Springer, Berlin, pp 189-201.

Westall, F., Cavalazzi, B., Lemelle, L., Marrocchi, Y., Rouzaud, J.N., Simionovici, A., Salomé, M., Mostefaoui, S., Andreazza, C., Foucher, F., Toporski, J., Jauss, A., Thiel, V., Southam, G., MacLean, L., Wirick, S., Hofmann, A., Meibom, A., Robert, F., and Défarge, C. (2011) Implications of in situ calcification for photosynthesis in a $\sim 3.3 \mathrm{Ga}$-old microbial biofilm from the Barberton greenstone belt, South Africa. Earth Planet Sci Lett 310:468-479.

Westall, F., Campbell, K.A., Bréhéret, F.G., Foucher, F., Gautret, P., Hubert, A., Sorieul, S., Grassineau, N., and Guido, D.M. (2015a) Complex microbe-sediment systems are ancient $(3.33 \mathrm{Ga})$ and flourished in a hydrothermal context. Geology 43:615-618.

Westall, F., Foucher, F., Bost, N., Bertrand, M., Loizeau, D., Vago, J.L., Kminek, G., Gaboyer, F., Campbell, K.A., Bréhéret, J-B., Gautret, P., and Cockell, C.S. (2015b) Biosignatures on Mars: what, where and how? Implications for the search for Martian life. Astrobiology 15:998-1029.

Williams, R.M., Grotzinger, J.P., Dietrich, W.E., Gupta, S., Sumner, D.Y., Wiens, R.C., Mangold, N., Malin, M.C., Edgett, K.S., Maurice, S., Forni, O., Gasnault, O., Ollila, A., Newsom, H.E., Dromart, G., Palucis, M.C., Yingst, R.A., Anderson, R.B., Herkenhoff, K.E., Le Mouélic, S., Goetz, W., Madsen, M.B., Koefoed, A., Jensen, J.K., Bridges, J.C., Schwenzer, S.P., Lewis, K.W., Stack, K.M., Rubin, D., Kah, L.C., Bell, J.F., III, Farmer, J.D., Sullivan, R., Van Beek, T., Blaney, D.L., Pariser, O., Deen,
R.G., and MSL Science Team. (2013) Martian fluvial conglomerates at Gale crater. Science 340:1068-1072.

Witasse, O, Vago, J.L., and Rodionov, D.S., and the ExoMars 2016 Principal Investigator Team. (2014) The ESARoscosmos ExoMars 2016 mission: a status report [abstract 1232]. In $8^{\text {th }}$ International Conference on Mars, Pasadena.

Address correspondence to: Jean-Luc Josset Space Exploration Institute Faubourg de l'Hôpital 68 2002 Neuchâtel Switzerland

E-mail: jean-luc.josset@space-x.ch

Submitted 5 June 2016 Accepted 5 March 2017

$\begin{aligned} & \text { Abbreviations Used } \\ \text { CLUPI } & =\text { Close-Up Imager } \\ \text { CSTM } & =\text { Core Sample Transportation Mechanism } \\ \text { FOV } & =\text { field of view }\end{aligned}$

